\title{
Dynamics of surface alloying promoted by cadmium underpotential deposition-anodic stripping cycles on irregular silver electrodeposits
}

\author{
M.E. Martins, A. Hernández-Creus *, R.C. Salvarezza, and A.J. Arvia * \\ Instituto de Investigaciones Fisicoquímicas Teóricas y Aplicadas (INIFTA), Universidad Nacional de La Plata, Sucursal 4, Casilla de Correo 16, \\ (1900) La Plata (Argentina)
}

(Received 16 November 1993; in revised form 17 February 1994)

\begin{abstract}
The underpotential deposition of $\mathrm{Cd}$ from dilute aqueous $5 \times 10^{-3} \mathrm{M} \mathrm{CdSO}_{4}+0.5 \mathrm{M} \mathrm{Na}_{2} \mathrm{SO}_{4}+0.01 \mathrm{M} \mathrm{H}_{2} \mathrm{SO}_{4}$ on $\mathrm{Ag}$ electrodeposits grown on polyfaceted $\mathrm{Pt}$ single-crystal microspheres was studied using potentiodynamic and potentiostatic techniques, transmission electron diffraction, scanning tunneling microscopy and X-ray photoelectron spectroscopy.

$\mathrm{Ag}$ electrodeposits were grown in $5 \times 10^{-3} \mathrm{M} \mathrm{Ag}_{2} \mathrm{SO}_{4}+0.5 \mathrm{M} \mathrm{Na}_{2} \mathrm{SO}_{4}+0.01 \mathrm{M} \mathrm{H}_{2} \mathrm{SO}_{4}$ at cathodic overpotentials $\eta_{\mathrm{c}}$ of $-0.06 \mathrm{~V}$ and $-0.58 \mathrm{~V}$ to form a columnar and dendritic $\mathrm{Ag}$ surface respectively.

Surface rearrangement processes involving the formation of $\mathrm{Cd}+\mathrm{Ag}$ alloys were studied by stripping voltammetry after the potential was held for a certain time at different preset values covering the potential range in which the degree of surface coverage by $\mathrm{Cd}$ atoms was less than or close to unity $\left(\theta_{\mathrm{c}} \leq 1\right)$ on both $\mathrm{Ag}$ surfaces. Surface diffusion and penetration of $\mathrm{Cd}$ atoms into bulk $\mathrm{Ag}$ for $\theta_{\mathrm{c}} \leq 1$ are discussed. A place-exchange mechanism is advanced to account for the kinetics of $\mathrm{Cd}+\mathrm{Ag}$ alloy formation.
\end{abstract}

\section{Introduction}

The early stages of metal phase growth of an epitaxial film imply the formation of an interfacial region which can be described by different models involving a discontinuous monolayer, a transition monolayer or a diffusive interface [1,2]. The diffusive interface is related to the formation of either a solid solution or an ordered alloy. In this case, lattice misfit and surface alloying can make the modelling of experimental data rather difficult.

Metal underpotential deposition (UPD) on foreign substrates can be considered as a condensation of metal atoms through adsorption or nucleation which precedes metal phase growth. Over the last few decades metal UPD on well-defined surfaces has become an important area of electrochemistry because results from these studies have provided the opportunity to explore possible links between electrochemical and gas phase

\footnotetext{
* Visiting Professor, Departamento de Química Física, Universidad de La Laguna, Tenerife, Spain.

* To whom correspondence should be addressed.
}

reactions at metal surfaces. This matter has been extensively reviewed in several publications [3-5].

According to thermodynamics, alloy formation is possible even in the UPD potential range in those systems forming stable intermetallic phases or exhibiting sufficient miscibility between substrate and adsorbate metals. This behavior has been observed in a number of polycrystalline [6-8] and single-crystal [9-16] substrates. Alloying in the UPD potential range can be explained by a place-exchange mechanism involving surface atoms and vacancies leading to dermalloying formation. Dermalloying kinetics differs, in principle, from the kinetics of metal penetration into the bulk substrate. Dermalloying kinetics at a grain-boundaryfree metal surface is usually determined by the surface diffusion rate of the slowest moving particles.

The electrocatalytic properties of dermalloys are still a matter of fundamental research. Their application in electrocatalysis depends on the possibility of producing dermalloyed electrodes, large surface area, for instance, by using very irregular dermalloyed fully accessible substrates. A large surface area of either columnar or dendritic electrodeposits can easily be produced at intermediate and high growth rates re- 
spectively $[17,18]$. Such electrodeposits have recently been considered as reference systems for describing irregular surface growth patterns predicted by theoretical models [19]. These two types of metallic electrodeposits exhibit a clear growth transition from a columnar to a dendritic pattern as the applied potential is moved in the direction of increasing the metal electrodeposition rate. Columnar and dendritic metal surfaces appear as suitable large surface area substrates for attempting dermalloy formation $[17,18]$.

This work is devoted to dermalloying and bulk alloy formation from $\mathrm{Cd}$ electrodeposition on irregular $\mathrm{Ag}$ substrates electrodeposited on polycrystalline Pt surfaces. Previous investigations related to this subject have shown that Cd UPD on Ag at potentials close to the $\mathrm{Cd} / \mathrm{Cd}^{2+}$ reversible electrode potential implies the formation of several $\mathrm{Cd}$ monolayers. The binary $\mathrm{Cd}+$ $\mathrm{Ag}$ system forms intermetallic phases [20], and $\mathrm{Cd}+\mathrm{Ag}$ alloys are thermodynamically stable in the Cd UPD potential range on $\mathrm{Ag}[9,10]$.

Two main aspects are considered in this work, namely substrate characterization by transmission electron diffraction (TED), scanning tunneling microscopy (STM) and different UPD reactions, and investigation of the $\mathrm{Cd}+\mathrm{Ag}$ dermalloy kinetics in aqueous acid solutions using electrochemical methods and X-ray photoelectron spectroscopy (XPS). Cd UPD at both rough columnar and dendritic $\mathrm{Ag}$ surfaces produces $\mathrm{Cd}+\mathrm{Ag}$ dermalloy films up to two monolayers (2 ML) thick for degrees of surface coverage by $\mathrm{Cd}$ atoms lower than unity $\left(\theta_{c} \leq 1\right)$. Dermalloy kinetics appear to be determined by the mobility of $\mathrm{Ag}$ surface atoms into a mobile $\mathrm{Cd}$ surface layer.

\section{Experimental}

\subsection{Electrode preparation}

Two types of Ag working electrodes (WEs), which were characterized by either a columnar or a dendritic topography, were used. In both cases, the Ag electrodeposits were grown on either a polyfaceted $\mathrm{Pt}$ single-crystal microsphere (apparent area $0.027 \mathrm{~cm}^{2}$ ) or a polycrystalline $\mathrm{Pt}$ plate (apparent area $2 \mathrm{~cm}^{2}$ ). Ag-plated Pt plate electrodes were specifically used for Auger and XPS analyses.

$\mathrm{Ag}$ electrodeposits were made from a $0.5 \mathrm{M} \mathrm{Na}_{2} \mathrm{SO}_{4}$

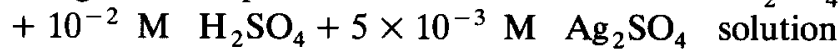
(solution I) under constant-potential conditions. Depending on the applied cathodic overvoltage $\eta_{\mathrm{c}}$, either a compact columnar $\left(\eta_{\mathrm{c}}=-0.06 \mathrm{~V}\right)$ [17] or a rough dendritic $\left(\eta_{c}=-0.58 \mathrm{~V}\right)$ [18] Ag electrodeposit was formed. The cathodic overpotential is defined as $\eta_{\mathrm{c}}=$ $E_{\mathrm{r}}-E_{\mathrm{d}}$, where $E_{\mathrm{r}}$ is the reversible potential of the $\mathrm{Ag} / \mathrm{Ag}^{+}$couple in solution $\mathrm{I}$ and $E_{\mathrm{d}}$ is the applied potential $\left(E_{\mathrm{r}}=0.38 \mathrm{~V} / \mathrm{SCE}\right.$ at $\left.25^{\circ} \mathrm{C}\right)$ [21]. Potentials in the text are referred to the saturated calomel electrode (SCE) scale. The value of the $\mathrm{Ag}$ electrodeposition charge density $q_{\mathrm{Ag}}$ was varied in the range $25 \mathrm{mC}$ $\mathrm{cm}^{-2}<q_{\mathrm{Ag}}<60 \mathrm{mC} \mathrm{cm}{ }^{-2}$. After preparation, the $\mathrm{Ag}$ coated WE was removed from the cell at $E_{\mathrm{d}}$, rinsed with Milli-Q* water and transferred to another electrochemical cell containing $0.5 \mathrm{M} \mathrm{Na}_{2} \mathrm{SO}_{4}+10^{-2} \mathrm{M}$ $\mathrm{H}_{2} \mathrm{SO}_{4}+5 \times 10^{-3} \mathrm{M} \mathrm{CdSO}{ }_{4}$ (solution II). The reversible potential of the $\mathrm{Cd} / \mathrm{Cd}^{2+}$ couple in solution II is $E_{\mathrm{r}}=-0.71 \mathrm{~V} / \mathrm{SCE}$ at $25^{\circ} \mathrm{C}$ [21]. The potential was then stepped to $E_{\mathrm{h}}=0.15 \mathrm{~V}$, i.e. a potential sufficiently negative to prevent oxidation of the $\mathrm{Ag}$ electrodeposit but positive enough to avoid Cd UPD on Ag.

The $\mathrm{Cd}+\mathrm{Ag}$ alloy ( $\alpha$ phase) electrodes were prepared by melting known amounts of $\mathrm{Ag}$ and $\mathrm{Cd}$ in a quartz tube under vacuum [22]. For this preparation, small-size high purity $\mathrm{Ag}$ and $\mathrm{Cd}$ grains were employed. Each lens-shaped alloy piece resulting from melting was machined to make square plate electrodes of apparent area about $1 \mathrm{~cm}^{2}$, with a metal stripe on one side to facilitate welding to a $\mathrm{Pt}$ lead. The $\mathrm{Cd}+\mathrm{Ag}$ alloy electrode was then mirror polished with alumina suspension of 1.0 and $0.3 \mu \mathrm{m}$ grit alumina in ethanol.

\subsection{Electrochemical measurements}

Electrochemical measurements were made in a conventional three-electrode glass cell comprising a WE, a large Pt gauze counter-electrode and a saturated calomel reference electrode conventionally assembled. Solutions were prepared from Merck p.a. chemicals and Milli- $Q^{*}$ water, and were kept under purified $\mathrm{N}_{2}$. Runs were made at $25^{\circ} \mathrm{C}$ under a $\mathrm{N}_{2}$ atmosphere.

Changes of $\mathrm{Ag}$ electrodeposits were followed by $\mathrm{Cd}$ UPD-anodic stripping cyclic voltammetry at $0.02 \mathrm{~V}$ $\mathrm{s}^{-1}$ between $E_{\mathrm{sc}}$ and $E_{\mathrm{sa}}$, the lower and upper switching potentials respectively. The value of $E_{\mathrm{sc}}=$ $-0.585 \mathrm{~V}$ was used in most of the runs to approach the $\theta_{c} \leq 1$ condition for $\mathrm{Cd}$ atom coverage.

After the first cyclic voltammogram (CV 1) had been recorded, the potential was scanned downwards from $0.15 \mathrm{~V}$ to $E_{\mathrm{h}}\left(-0.585 \mathrm{~V}<E_{\mathrm{h}}<0.15 \mathrm{~V}\right)$, and then held at $E_{\mathrm{h}}$ for a preset time $t_{\mathrm{h}}\left(60 \mathrm{~s}<t_{\mathrm{h}}<30 \mathrm{~h}\right)$. Subsequently, the cyclic voltammogram was continued to obtain the second anodic stripping voltammogram (CV 2) and so on. The comparison between CV 1 and CV 2 allowed us to infer possible rearrangements at the $\mathrm{Ag}$ surface produced by potential holding at $E_{\mathrm{h}}$ in the time $t_{\mathrm{h}}$. Finally, in all cases the potential cycling was continued until the initial stable voltammogram was recovered.

Cd UPD-anodic stripping voltammetry was also run on $\mathrm{Cd}+\mathrm{Ag}$ alloy WE, with the intention of correlating 
the voltammetric features found for these electrodes with those resulting from $\mathrm{Cd}$ UPD on $\mathrm{Ag}$ electrodes under certain operating conditions. Differences could be assigned to formation of a $\mathrm{Cd}+\mathrm{Ag}$ alloy.

\subsection{Surface area determination}

The real surface area of $\mathrm{Pt}$ substrates was measured by the $\mathrm{H}$ atom electrosorption voltammetric charge in $0.5 \mathrm{M} \mathrm{H}_{2} \mathrm{SO}_{4}$ at $0.1 \mathrm{~V} \mathrm{~s}^{-1}$, covering the $-0.21 \mathrm{~V}$ to $1.23 \mathrm{~V}$ range. For this purpose, the charge density $q_{\mathrm{M}}$ of the $\mathrm{H}$ adatom monolayer (ML) on Pt was taken as $0.21 \mathrm{mC} \mathrm{cm}^{-2}$. Otherwise, the surface area of $\mathrm{Ag}$ electrodeposits was evaluated from the Cd UPD-anodic stripping charge of $\mathrm{CV} 1$ between $0.15 \mathrm{~V}$ and $-0.585 \mathrm{~V}$, taking $q_{\mathrm{M}}=0.42 \mathrm{mC} \mathrm{cm}^{-2}$ for the Cd ML.

\subsection{Surface characterization}

Surface characterization was based upon Pb UPD, TED and STM data.

\subsection{1. $\mathrm{Pb}$ underpotential deposition}

Columnar and dendritic $\mathbf{A g}$ surfaces were characterized by $\mathrm{Pb}$ UPD-anodic stripping cyclic voltammetry in $0.1 \mathrm{M} \mathrm{NaClO}_{4}+5 \times 10^{-3} \mathrm{M} \mathrm{HClO}_{4}+10^{-2} \mathrm{M}$ $\mathrm{Pb}\left(\mathrm{ClO}_{4}\right)_{2}$ at $0.01 \mathrm{~V} \mathrm{~s}^{-1}$ in the $0 \mathrm{~V}$ to $-0.43 \mathrm{~V}$ range. These runs were performed according to the electrochemical procedure already described.

\subsubsection{Transmission electron diffraction}

The crystallographic structure of small Ag aggregates prepared by electrochemical methods was determined by TED. This technique was preferred to other $X$-ray diffraction techniques which are not suitable for determining crystal morphology and relative orientation on unusually small crystalline aggregates. In such a case, macroscopic specimens for X-ray diffraction (10$100 \mathrm{mg}$ ) are usually made up of an extremely large number $\left(10^{13}-10^{15}\right)$ of individual particles, where all morphological and orientational features, as they appear in the diffraction patterns, are necessarily smeared and masked by the random nature of their mutual orientations. TED, however, is ideally suited for focusing on individual crystal aggregates $\left( \pm 10^{-16} \mathrm{~g}\right)$ of the sample, thus leading to the possibility of conducting unequivocal morphological studies.

The electron diffractograms were obtained with a Siemens Elmiskop 101 electron microscope furnished with a liquid $\mathrm{N}_{2}$ anti-contamination device and a cooling stage at $100 \mathrm{kV}$ acceleration potential. Double-condenser illumination conditions were applied, with the first condenser lens fully energized and a $20 \mu \mathrm{m}$ aperture fitted to the second lens [23]. In this way the influence of spherical aberration in the second condenser was kept to a minimum, and the irradiated regions of the specimens were restricted to very small surface areas $\left( \pm 1 \mu \mathrm{m}^{2}\right)$. Calibration of the microscope column to establish the diffraction constant was accomplished by recording electron diffraction patterns of vacuum-deposited Au films. Specimen preparation was carried out by electrodepositing $\mathrm{Ag}$ dendrites on $\mathrm{Pt}$ at $\eta=-0.58 \mathrm{~V}$ in solution I. Ag dendrites were rinsed with Milli-Q* water and deposited on Au films.

\subsubsection{Scanning tunneling microscopy}

STM images of columnar and dendritic Ag electrodeposits prepared as described in Section 2.1 were acquired using a McAllister scanning tunneling microscope operating in ambient conditions. Pt + Ir tips used for STM imaging were made by cutting Pt $+\mathrm{Ir}$ wires $0.11 \mathrm{~mm}$ in diameter. The images were obtained by applying a $0.06 \mathrm{~V}$ bias voltage with the tip positive at a constant current of 1-2 nA.

The STM calibration was performed through the HOPG surface lattice. At the highest resolution $(4 \mathrm{~nm}$ $\times 4 \mathrm{~nm}$ ) the typical hexagonal array of $C$ atoms, where only three out of the six $\mathrm{C}$ atoms in the graphite lattice leading to nearest-neighbor distances of $0.24 \pm 0.02 \mathrm{~nm}$, was observed. In addition, the honeycomb structure with a $C-C$ distance of $0.14 \pm 0.02 \mathrm{~nm}$ was also resolved.

Data were acquired at a fully automated workstation and stored as digitized images with $200 \times 200$ or $400 \times 400$ pixels.

\section{5. $X$-ray photoelectron spectroscopy}

XPS analysis was carried out in an ultrahigh vacuum (UHV) chamber at a base pressure lower than $10^{-9}$ Torr using Vacuum Generator Scientific ESCA 3 Mark II equipment. XPS data were obtained with $\mathrm{Mg}$ $\mathrm{K} \alpha$ radiation $(1253.6 \mathrm{eV})$ at an angle of $60^{\circ}$ between the surface normal and the analyser lens in order to increase the surface sensitivity of the spectra. The collection time was between $20 \mathrm{~s}$ and $60 \mathrm{~s}$. WE samples coated with columnar Ag were removed from the cell by holding the potential at different preset $E_{\mathrm{h}}$ values, rinsing with $\mathrm{N}_{2}$-saturated Milli-Q* ${ }^{*}$ water and drying under $\mathrm{N}_{2}$.

\section{Results}

\subsection{Characterization of Ag working electrodes}

\subsection{1. $P b$ underpotential deposition}

The $\mathrm{Pb}$ UPD-anodic stripping voltammograms recorded on columnar Ag electrodes (Fig. 1(a)) show a pair of small broad peaks covering the $-0.24 \mathrm{~V}$ to $-0.32 \mathrm{~V}$ range [17]. The $\mathrm{Pb}$ UPD-anodic stripping voltammograms of $\mathrm{Ag}$ dendritic electrodes (Fig. 1(b)) 
exhibit a large sharp pair of peaks located at $-0.3 \mathrm{~V}$ with shoulders at $-0.26 \mathrm{~V}$. In addition, a small pair of peaks is also observed at $-0.4 \mathrm{~V}$, a potential which is close to the $\mathrm{Pb} / \mathrm{Pb}^{2+}$ reversible electrode potential. The voltammograms depicted in Fig. 1(b) closely resemble those recorded at a stepped $\mathrm{Ag}(111)$ surface $[24,25]$.

\subsubsection{Transmission electron diffraction data}

A typical TED pattern of $\mathrm{Ag}$ dendrites mounted onto fine-grained $\mathrm{Au}$ polycrystalline films (Fig. 2) shows continuous rings corresponding to the polycrystalline $\mathrm{Au}$ film, while the discrete spots correspond to the $\mathrm{Ag}$ dendrites. The following features can be distinguished from the TED patterns.

Only $\mathrm{Ag}(220)$ single-crystal reflections are observed. This means that $\mathrm{Ag}(220)$ and the corresponding $\mathrm{Ag}(110)$
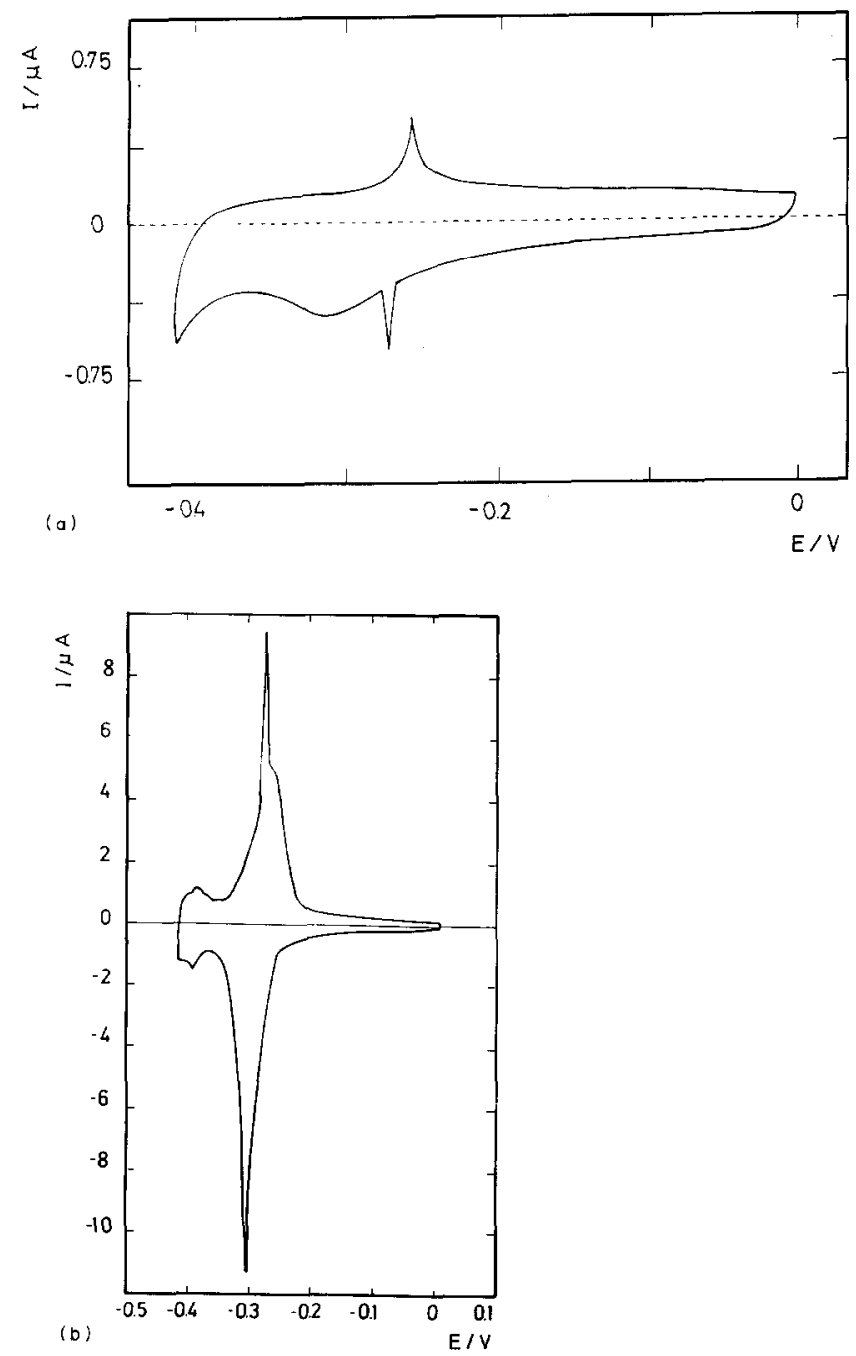

Fig. 1. Cyclic voltammograms of $\mathrm{Pb}$ UPD-anodic stripping in $10^{-1} \mathrm{M}$ $\mathrm{NaClO}_{4}+5 \times 10^{-3} \mathrm{M} \mathrm{HClO}_{4}+10^{-2} \mathrm{M} \mathrm{Pb}\left(\mathrm{ClO}_{4}\right)_{2}$ at $0.01 \mathrm{~V} \mathrm{~s}^{-1}$ and $25^{\circ} \mathrm{C}$ : (a) columnar Ag WE; (b) dendritic Ag WE.

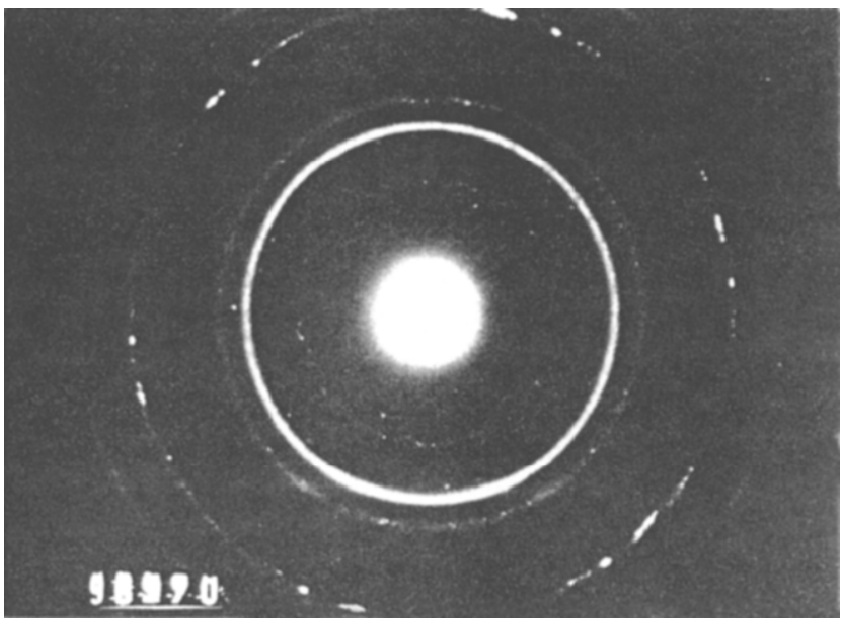

Fig. 2. Transmission electron diffractogram of a $\mathrm{Ag}$ dendritic deposit from solution I at $\eta_{\mathrm{c}}=-0.58 \mathrm{~V}$ and $25^{\circ} \mathrm{C}$.

planes are normal to the substrate surface, i.e. the [220] and [110] vectors are normal to the electron beam direction. No four-fold symmetry is observed, in agreement with the preceding conclusion.

Other intense reflections of $\operatorname{Ag}(111), \operatorname{Ag}(200)$ and $\mathrm{Ag}(311)$ are conspicuously absent from the diffraction patterns. This precludes an unequivocal definition of the orientation of crystallites, since with only two points available $((200)$ and $(000))$ it is not possible to define the position of the [220]-pole axis around which crystallites can adopt any orientation.

The main set of $\mathrm{Ag}(220)$ reflections are related to each other by a six-fold axis of symmetry. In addition, each major reflection shows a weaker satellite at about $10^{\circ}$, and even weaker streaks within this $10^{\circ}$ range. The presence of hexagonal symmetry in the diffraction patterns immediately indicates the growth of ordered $\mathrm{Ag}$ aggregates, crystallographically related to each other by the six-fold axis, as no possible orientation of an individual cubic single crystal can give rise to a set of $60^{\circ}$ reflections related to $\mathrm{Ag}(220)$. Furthermore, secondary nucleation may be responsible for the weaker satellite reflections shown up in such a regular fashion.

\subsubsection{Scanning tunneling microscopy data}

STM images of the $\mathrm{Ag}$ electrodeposits grown at $\eta_{\mathrm{c}}=-0.06 \mathrm{~V}$ (Fig. 3) show nanometer-size elements which correspond to the column tips forming the deposit structure [17]. The average size of these rounded elements is close to $20 \mathrm{~nm}$. In contrast with other columnar structures, such as those resulting from vapor-deposited Au films [26], no preferred orientation of the small columns are observed in the STM images. The structure of the Ag electrodeposits grown at this potential closely resembles the columnar structure of 
$\mathrm{Au}$ and Pt electrodeposits grown from the electroreduction of their respective hydrous oxides [27,28].

The surfaces of dendritic $\mathrm{Ag}$ electrodeposits grown at $\eta_{\mathrm{c}}=-0.58 \mathrm{~V}$ show large differences in height, making the STM imaging of these specimens difficult. Nevertheless, stable tunneling conditions can be obtained in small domains, typically of dimensions $40 \mathrm{~nm}$ $\times 40 \mathrm{~nm}$. These images show terraces and multipleheight steps (Fig. 4(a)) intersecting at $30^{\circ}, 60^{\circ}$ and $120^{\circ}$ (Fig. 4(b)). The surface topography of these domains appears to be consistent with a stepped $\mathrm{Ag}(111)$ surface.

\subsection{Voltammetric data related to $C d$ electrodeposition- anodic stripping}

Conventional Cd UPD voltammetry shows at least two sharp conjugated pairs of peaks and the contribution of an additional broad pair of peaks on both columnar (Fig. 5(a)) and dendritic (Fig. 9(a) below) Ag. It should be noted that the voltammetric features mentioned above are better defined for dendritic Ag electrodes. Generally, these results agree with those previously reported for $\mathrm{Cd}$ atom electrodeposition on both $\mathrm{Ag}$ polycrystalline surfaces and well-defined single crystal faces $[9,10]$.

The charge resulting from the voltammograms exceeds the charge density of the Cd UPD ML. However, it is possible to evaluate that the charge density of the Cd UPD ML when $E_{\mathrm{sc}}$ is close to $-0.585 \mathrm{~V}$.

\subsubsection{Cd underpotential deposition-anodic stripping} on columnar Ag electrodeposits

The Cd UPD-anodic stripping CVs at compact columnar $\mathrm{Ag}$ electrodeposits run at $0.02 \mathrm{~V} \mathrm{~s}^{-1}$ from $0.150 \mathrm{~V}$ to $-0.585 \mathrm{~V}$ (Fig. 5) in solution II show a continuous increase in the cathodic current with a

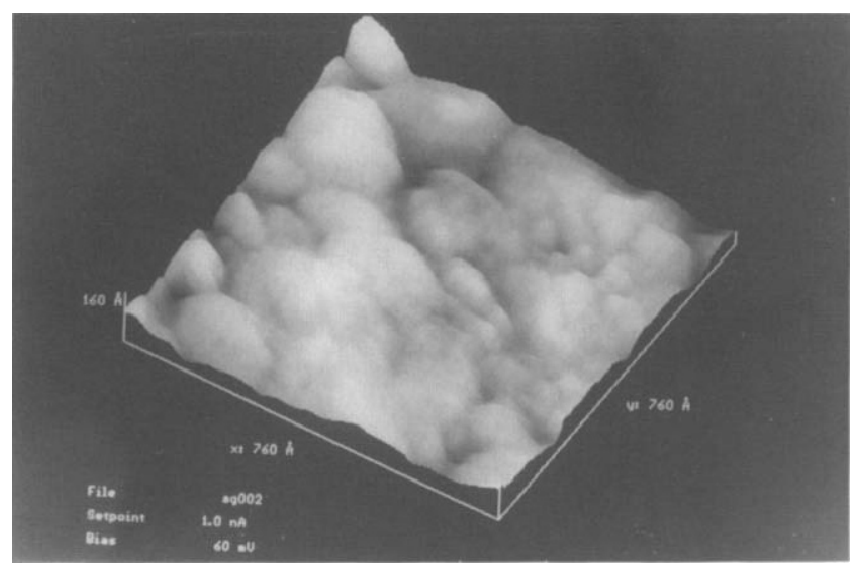

Fig. 3. Three-dimensional STM image $(76 \mathrm{~nm} \times 76 \mathrm{~nm})$ of a columnar $\mathrm{Ag}$ electrodeposit from solution I at $\eta_{\mathrm{c}}=-0.06 \mathrm{~V}$.

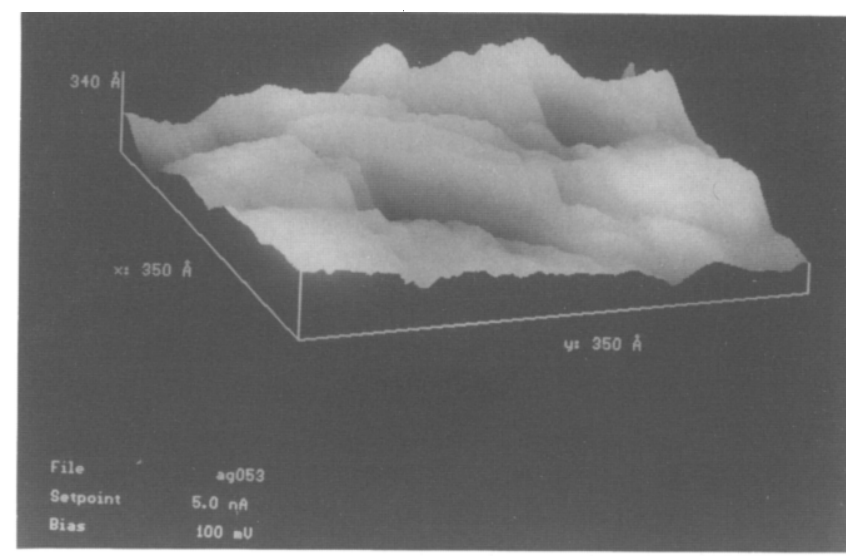

(a)

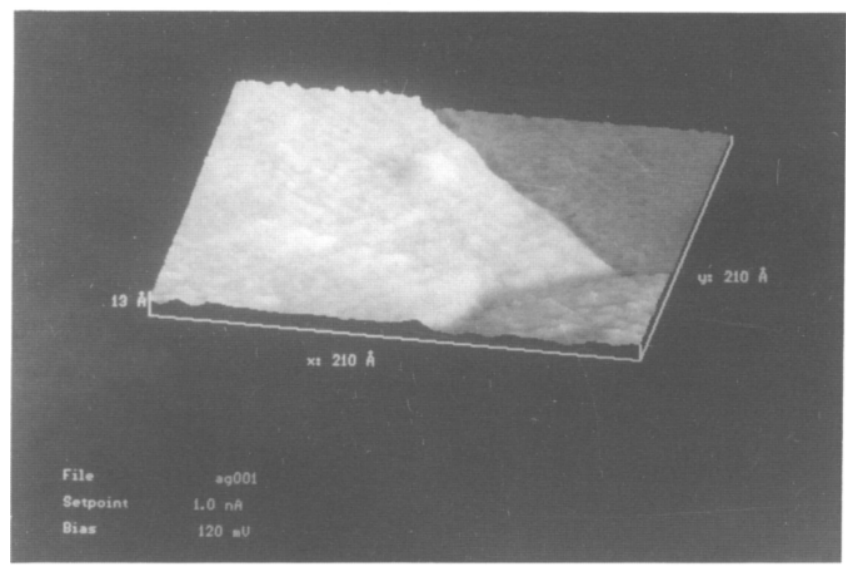

(b)

Fig. 4. STM images of dendritic Ag electrodeposits from solution I at $\eta_{\mathrm{c}}=-0.58 \mathrm{~V}$ : (a) three-dimensional image $(35 \mathrm{~nm} \times 35 \mathrm{~nm}$ ); (b) top view image $(21 \mathrm{~nm} \times 21 \mathrm{~nm})$.

small current inflection (not seen in the Fig. 5) near the lower switching potential $E_{\mathrm{sc}}$ and a trend to displaying a hump in the $-0.165 \mathrm{~V}$ to $-0.385 \mathrm{~V}$ range. Conversely, the reverse potential scan exhibits broad peaks Ia at $-0.425 \mathrm{~V}$ and IIa at $-0.2 \mathrm{~V}$. The values of the area and of the roughness factor for the columnar Ag electrodeposit ( $A=0.074 \mathrm{~cm}^{2}$ and $R=2.7$ respectively) have been calculated from the anodic and the cathodic voltammetric charges $Q_{\mathrm{a}}$ and $Q_{\mathrm{c}}$, assuming $q_{\mathrm{M}}=0.42 \mathrm{mC} \mathrm{cm}^{-2}$ for the Cd ML charge density, a figure which results from a process involving two electrons per site per adsorbate species on an ideal smooth surface.

Similar runs made at different $E_{\text {sc }}$ show that both $Q_{\mathrm{a}}$ and $Q_{\mathrm{c}}$ decrease as $E_{\mathrm{sc}}$ is positively shifted, although $Q_{\mathrm{a}} / Q_{\mathrm{c}} \approx 1$ irrespective of $E_{\mathrm{sc}}$. The effect of $E_{\mathrm{sc}}$ on $Q_{\mathrm{a}}$ and $Q_{\mathrm{c}}$ is accompanied by changes in the reversibility of the anodic and cathodic reactions, as can be seen, for instance, by plotting both $\theta_{\mathrm{a}}$ and $\theta_{\mathrm{c}}$ vs. $E_{\mathrm{sc}}$ (Fig. 6), where $\theta_{\mathrm{a}}$ and $\theta_{\mathrm{c}}$ are the degrees of $\mathrm{Ag}$ 
surface coverage assigned to $\mathrm{Cd}$ atoms at the anodic and cathodic reaction respectively. These values of $\theta$ are referred to $q_{\mathrm{ML}}=0.42 \mathrm{mC} \mathrm{cm}^{-2}$. Within the same range of $\theta$, the $\theta_{\mathrm{c}}$ vs. $E_{\mathrm{sc}}$ plot shows a continuous decrease from unity to zero, whereas the $\theta_{\mathrm{a}}$ vs. $E_{\mathrm{sc}}$ plot presents a sigmoid shape. This difference suggests that processes involved in each Cd UPD-anodic stripping cycle are not strictly complementary. The reason for this has to be considered in terms of a rather complex reaction, which is anodic or cathodic or both.

\subsubsection{The influence of $E_{h}$ on $C d$ anodic stripping} voltammograms. The $\mathrm{Cd}$ anodic stripping voltammograms are sensitive to $E_{\mathrm{h}}$ and $t_{\mathrm{h}}$. Let us consider the influence of $t_{\mathrm{h}}$ on the voltammograms at different $E_{\mathrm{h}}$. Thus, when $E_{\mathrm{h}}=-0.39 \mathrm{~V}$, i.e. for $\theta_{\mathrm{c}}=0.4$ (Fig. 7), from the comparison between the voltammograms run

(a)
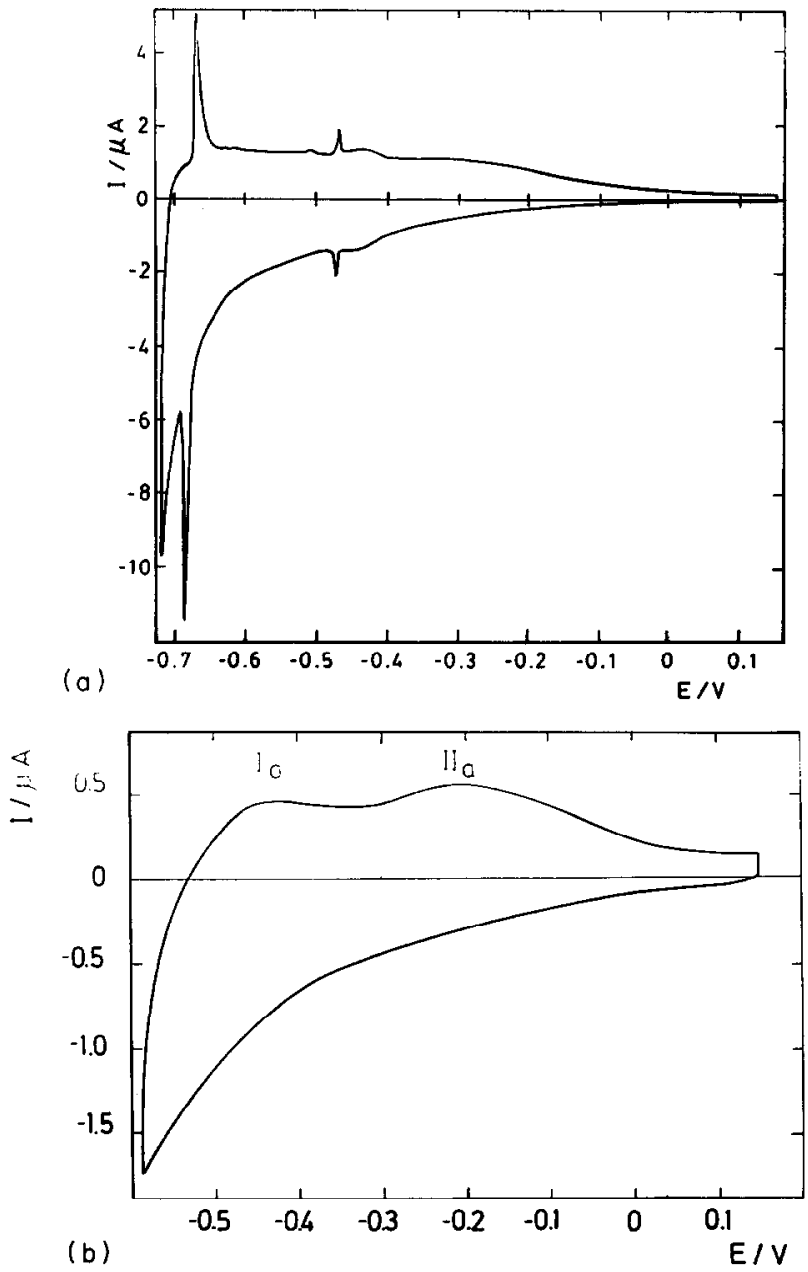

Fig. 5. Cyclic voltammogram of Cd UPD-anodic stripping for columnar $\mathrm{Ag} \mathrm{WE}$ in solution II at $0.02 \mathrm{~V} \mathrm{~s}^{-1}, q_{\mathrm{Ag}}=50 \mathrm{mC} \mathrm{cm}^{-2}$ and $25^{\circ} \mathrm{C}$ : (a) $E_{\mathrm{sc}}=-0.705 \mathrm{~V}$; (b) $E_{\mathrm{sc}}=-0.585 \mathrm{~V}$.

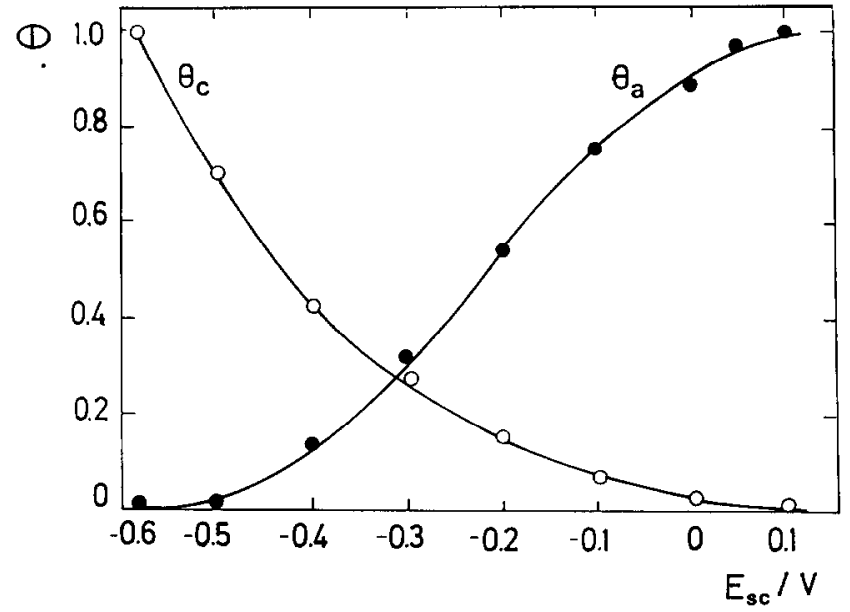

Fig. 6. Plots of $\theta_{\mathrm{a}}$ vs. $E_{\mathrm{sc}}$ and $\theta_{\mathrm{c}}$ vs. $E_{\mathrm{sc}}$ for Cd UPD-anodic stripping in solution II at $0.02 \mathrm{~V} \mathrm{~s}^{-1}$ and $25^{\circ} \mathrm{C}$ for columnar $\mathrm{Ag} \mathrm{WE}$.

after holding the potential at $E_{\mathrm{h}}$ for $t_{\mathrm{h}}$ and $\mathrm{CV} 1$ without holding the potential at $E_{\mathrm{h}}$ (Fig. 5(b)), the following features can be observed. For $5 \mathrm{~min}<t_{\mathrm{h}}<$ $60 \mathrm{~min}$, the decrease in the height of peak Ia is comparable to the increase in the height of peak IIa (Fig. 7(a)). Otherwise, for $t_{\mathrm{h}}>1 \mathrm{~h}$ peak IIIa at ca. $0.1 \mathrm{~V}$ develops and its height increases with $t_{\mathrm{h}}$ (Fig. 7(b)). Finally, for $t_{\mathrm{h}}>4 \mathrm{~h}$, peaks IIa and IIIa tend to overlap and a stationary $\mathrm{CV}$ is approached (Figs. $7(\mathrm{c})$ and $7(\mathrm{~d})$ ). Then the voltammetric charge distribution results in 0.2 ML for peak Ia (weakly bound adsorbate) and 0.8 ML for other contributions (strongly bound adsorbate), leading to $\theta_{\mathrm{a}} \approx 1 \mathrm{ML}$. This behavior is opposite to that found for conventional Cd UPD-anodic stripping CVs, as in this case about $80 \%$ of Cd UPD appears as a strongly bound adsorbate.

Similar runs were made by setting $E_{\mathrm{h}}=-0.575 \mathrm{~V}$, i.e. $\theta_{\mathrm{c}}=0.96$ (Fig. 8), where it was found that, for $1 \mathrm{~min}<t_{\mathrm{h}}<10 \mathrm{~min}$, the increase in the height of peaks Ia and IIa are about the same, nearly irrespective of $t_{\mathrm{h}}$ (Fig. 8(a)). However, for $t_{\mathrm{h}}>10 \mathrm{~min}$ (Fig. 8(b)), peak Ia turns into the sharp peak $I_{a}^{\prime}$ at $-0.365 \mathrm{~V}$. These changes become more noticeable for $t_{\mathrm{h}} \approx 4 \mathrm{~h}$ (Fig. 8(c)) where the height of peak $I_{a}^{\prime}$ increases and its potential shifts positively as $t_{\mathrm{h}}$ is increased. Furthermore, peak IIIa at $0.05 \mathrm{~V}$ and complex peak Ic $^{\prime}$ at ca. $-0.4 \mathrm{~V}$ can also be observed. The value of $Q_{\mathrm{a}}$ becomes equivalent to $1.9 \mathrm{ML}$, and $\mathrm{CV}$ features obtained for $t_{\mathrm{h}} \geq 4 \mathrm{~h}$ substantially differ from those found for $t_{\mathrm{h}}=0$. For $t_{\mathrm{h}} \approx 14 \mathrm{~h}$ (Fig. 8(d)), CV 1 shows a well-defined peak $r_{a}^{\prime}$, and after ca. five CVs the features closely resembles those obtained in the Cd UPDanodic stripping voltammogram run on a dendritic $\mathrm{Ag}$ electrode under comparable conditions, as described below. 
3.2.2. Cd underpotential deposition-anodic stripping on dendritic Ag electrodeposits

The Cd UPD-anodic stripping CVs resulting from dendritic Ag electrodeposits at $0.02 \mathrm{~V} \mathrm{~s}^{-1}$ in the $0.15 \mathrm{~V}$ to $-0.58 \mathrm{~V}$ range (Fig. 9(a)) show symmetric conjugated pairs of peaks in the $-0.425 \mathrm{~V}$ to $-0.6 \mathrm{~V}$ range. The conjugated pair of peaks at $-0.46 \mathrm{~V}$ is very sharp, and the corresponding $\theta_{\mathrm{a}}$ and $\theta_{\mathrm{c}}$ vs. $E_{\mathrm{sc}}$ plots (Fig. 9(b)) are much more symmetrical than those resulting from compact columnar-structured $\mathrm{Ag}$ electrodeposits (Fig. 6). From these results it can be concluded that the Cd UPd-anodic stripping processes on dendritic $\mathrm{Ag}$ WEs behave as reversible surface electrochemical reactions.

From the values of $Q_{\mathrm{a}}$ and $Q_{\mathrm{c}}$, and assuming $q_{\mathrm{M}}=$ $0.42 \mathrm{mC} \mathrm{cm}^{-2}$ for the $\mathrm{Cd}$ monolayer charge density, the area and the roughness factor of the dendritic $\mathrm{Ag}$ electrodeposit are obtained as $A=0.15 \mathrm{~cm}^{2}$ and $R=$ 5.5. These figures are twice the values of those found for columnar Ag electrodeposits.

\subsubsection{The influence of $E_{h}$ on $C d$ anodic stripping} voltammograms. Runs including a potential holding at $E_{\mathrm{h}}=-0.40 \mathrm{~V}$, i.e. $\theta_{\mathrm{c}} \approx 0.27$, show that the first $\mathrm{CV}$ after holding the potential at $E_{\mathrm{h}}$ remains almost un- changed for $t_{\mathrm{h}}<1 \mathrm{~h}$ (Fig. 10(a)), whereas for $t_{\mathrm{h}}>1 \mathrm{~h}$ it exhibits a decrease in both hcight and sharpness of all peaks compared with the first $\mathrm{CV}$ obtained without holding the potential at $E_{\mathrm{h}}$. Simultaneously, the broad peak IIIa at $0.025 \mathrm{~V}$ starts to grow (Fig. 10(b)) and its charge increases with $t_{\mathrm{h}}$, in contrast with the charge involved in the $-0.425 \mathrm{~V}$ to $-0.6 \mathrm{~V}$ range. However, for $t_{\mathrm{h}}>10 \mathrm{~h}$ a steady CV with $\theta_{\mathrm{a}} \approx 1 \mathrm{ML}$ is attained. This surface coverage is distributed as $\theta_{\text {Cd }}$ (peak IIIa) $\approx 0.27 \mathrm{ML}$ and $\theta_{\mathrm{Cd}}$ (other contributions) $\approx 0.73 \mathrm{ML}$. Hence the relative contribution of weakly bound $\mathrm{Cd}$ species to dendritic Ag WEs has been considerably increased compared with compact columnar Ag WE (see Section 3.2.1.1).

Similar runs were performed by setting $E_{\mathrm{h}}=$ $-0.47 \mathrm{~V}$, i.e. $\theta_{\mathrm{c}} \approx 0.6$ (Fig. 11). For $0<t_{\mathrm{h}}<30 \mathrm{~min}$, peak $I_{a}^{\prime}$ at $-0.365 \mathrm{~V}$ can be observed (Fig. 8(c)) (see Section 3.2.1.1), and for $t_{\mathrm{h}}>1 \mathrm{~h}$ it develops a small shoulder at ca. $-0.275 \mathrm{~V}$ and peak IIIa starts to grow at $0.025 \mathrm{~V}$. Finally, for $t_{\mathrm{h}}>14 \mathrm{~h}$ peaks Ia', IIa' and IIIa are seen (Fig. 11), and after a very prolonged cyclic voltammetric treatment, the entire $\mathrm{CV}$ approaches that shown in Fig. 9(a). Throughout these experiments, the value of $\theta_{\mathrm{a}}$ continuously increases from $1 \mathrm{ML}$ to $2 \mathrm{ML}$ as $t_{\mathrm{h}} \rightarrow \infty$. Results from these runs are assembled in Table 1 including the value of $Q_{\mathrm{a}}$ for peak Ia and the

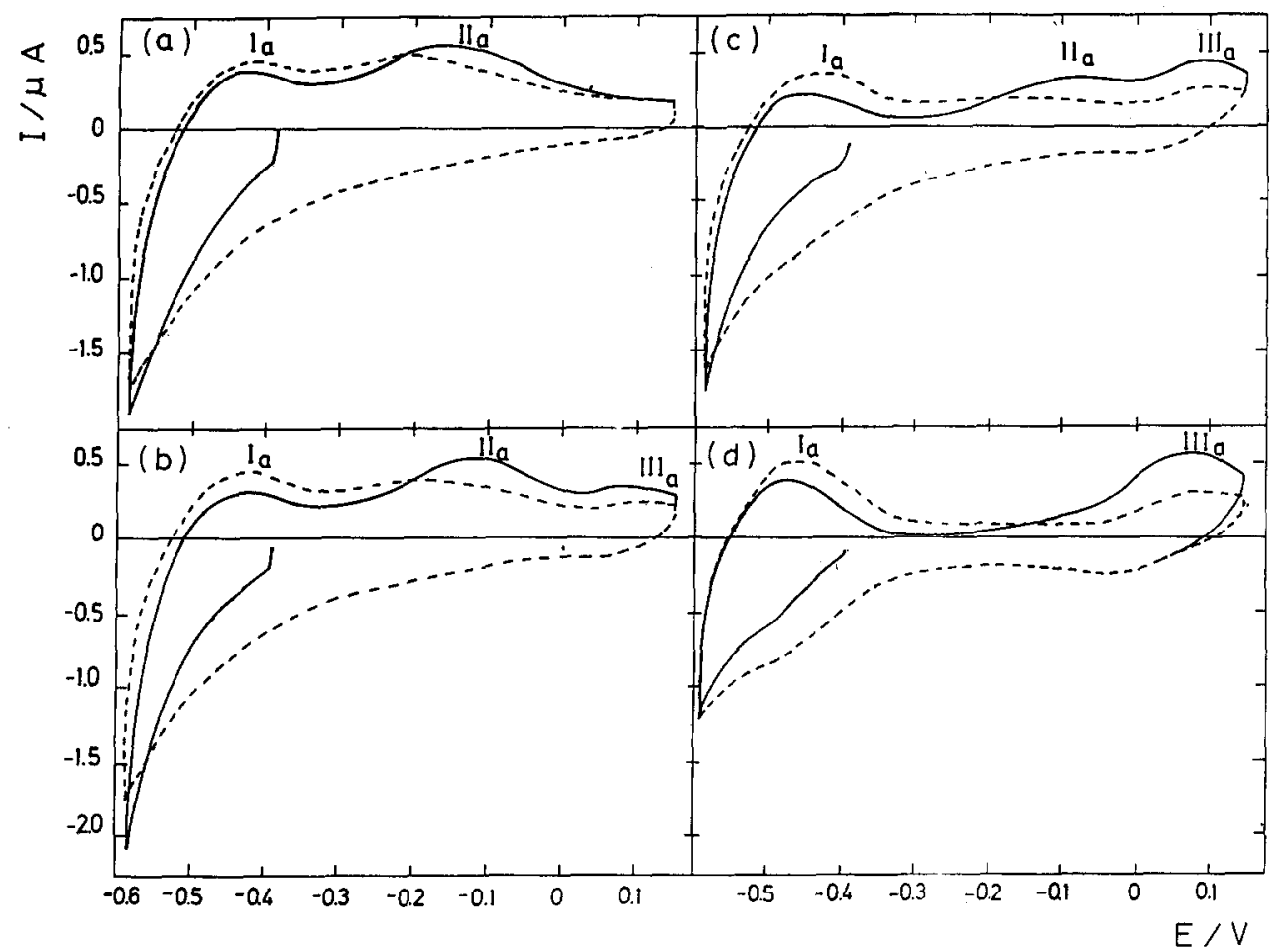

Fig. 7. Cyclic voltammograms of Cd UPD-anodic stripping for columnar $\mathrm{Ag}$ WEs, at $0.02 \mathrm{~V} \mathrm{~s}^{-1}$ including a potential holding at $E_{\mathrm{h}}=-0.39 \mathrm{~V}$ applied in the negative-going potential scan during different times $t_{\mathrm{h}}$ at $25^{\circ} \mathrm{C}(-\mathrm{CV} 1$; $--\mathrm{CV} 2)$ : (a) $t_{\mathrm{h}}=16 \mathrm{~min}$; (b) $t_{\mathrm{h}}=2 \mathrm{~h}$; (c) $t_{\mathrm{h}}=4 \mathrm{~h} ;$ (d) $t_{\mathrm{h}}=14 \mathrm{~h}$. 
$Q_{t}^{\text {upd }} / Q_{t=0}^{\text {upd }}$ ratio, where $Q_{t}^{\text {upd }}$ and $Q_{t=0}^{\text {upd }}$ stand for the residual and the initial UPD Cd charges respectively.

Voltammograms resulting from $E_{\mathrm{h}}=-0.575 \mathrm{~V}$, i.e. $\theta_{c} \approx 1$, largely resemble those obtained on compact columnar $\mathrm{Ag} \mathrm{WE}$ at the same $E_{\mathrm{h}}$, although the voltammetric features of the dendritic $\mathrm{Ag}$ WE depend on whether $t_{\mathrm{h}}$ is smaller or larger than a critical time $t_{\mathrm{c}}$ $\left(t_{\mathrm{c}} \approx 10 \mathrm{~min}\right.$ ) (Fig. 12). For $t_{\mathrm{h}}<t_{\mathrm{c}}$ (Fig. 12(a)) the Cd anodic stripping charge resulting from $\mathrm{CV} 1$ exceeds that derived from the $\mathrm{CV}$ without holding the potential at $E_{\mathrm{h}}$, although the shape and distribution of peaks, including peak $I_{a}^{\prime}$ at $-0.365 \mathrm{~V}$, remain almost the same. Otherwise, for $t_{\mathrm{h}}>t_{\mathrm{c}}$ (Fig. 12(b)) the height of peak Ia' increases, but a poorer definition of Cd UPD peaks compared with those shown in Fig. 12(a) can be seen. For $t_{\mathrm{h}}>1 \mathrm{~h}$ peak $\mathrm{I}_{\mathrm{a}}^{\prime}$ is defined, including its splitting into two peaks centered at $-0.355 \mathrm{~V}$ and at $-0.375 \mathrm{~V}$ (Fig. 12(c)). These CV features are also very sensitive to $E_{\mathrm{h}}$. Finally, a stationary Cd anodic strip- ping voltammogram is attained for $t_{\mathrm{h}} \rightarrow 12 \mathrm{~h}$, and in this case $\theta_{\mathrm{Cd}} \rightarrow 2 \mathrm{ML}$. It should be noted that the conjugated pair of peaks IIIa/IIIc at ca. $0.025 \mathrm{~V}$ and $\theta_{\mathrm{Cd}}$ values slightly greater than $2 \mathrm{ML}$ can be obtained for $t_{\mathrm{h}}>10 \mathrm{~h}$. Data derived from these runs are summarized in Table 2.

For both columnar and rough $\mathrm{Ag}$ WEs, neither shape nor voltammetric charge changes have been observed after $24 \mathrm{~h}$ potential cycling at $0.02 \mathrm{~V} \mathrm{~s}^{-1}$ between $0.15 \mathrm{~V}$ and $-0.585 \mathrm{~V}$, i.e. in the Cd UPD-anodic stripping potential range. These results suggest that both the area and the structure of the $\mathrm{Ag}$ surface remain stable during long-term potential cycling. Presumably, the Ag surface atom mobility becomes sufficiently fast to expect any long-time-range surface roughness decay. Conversely, the $\mathrm{CV}$ changes produced by short-time potential cycling indicate possible electrode surface changes mainly caused by potential holding at $E_{\mathrm{h}}$ during $t_{\mathrm{h}}$. These changes may reflect

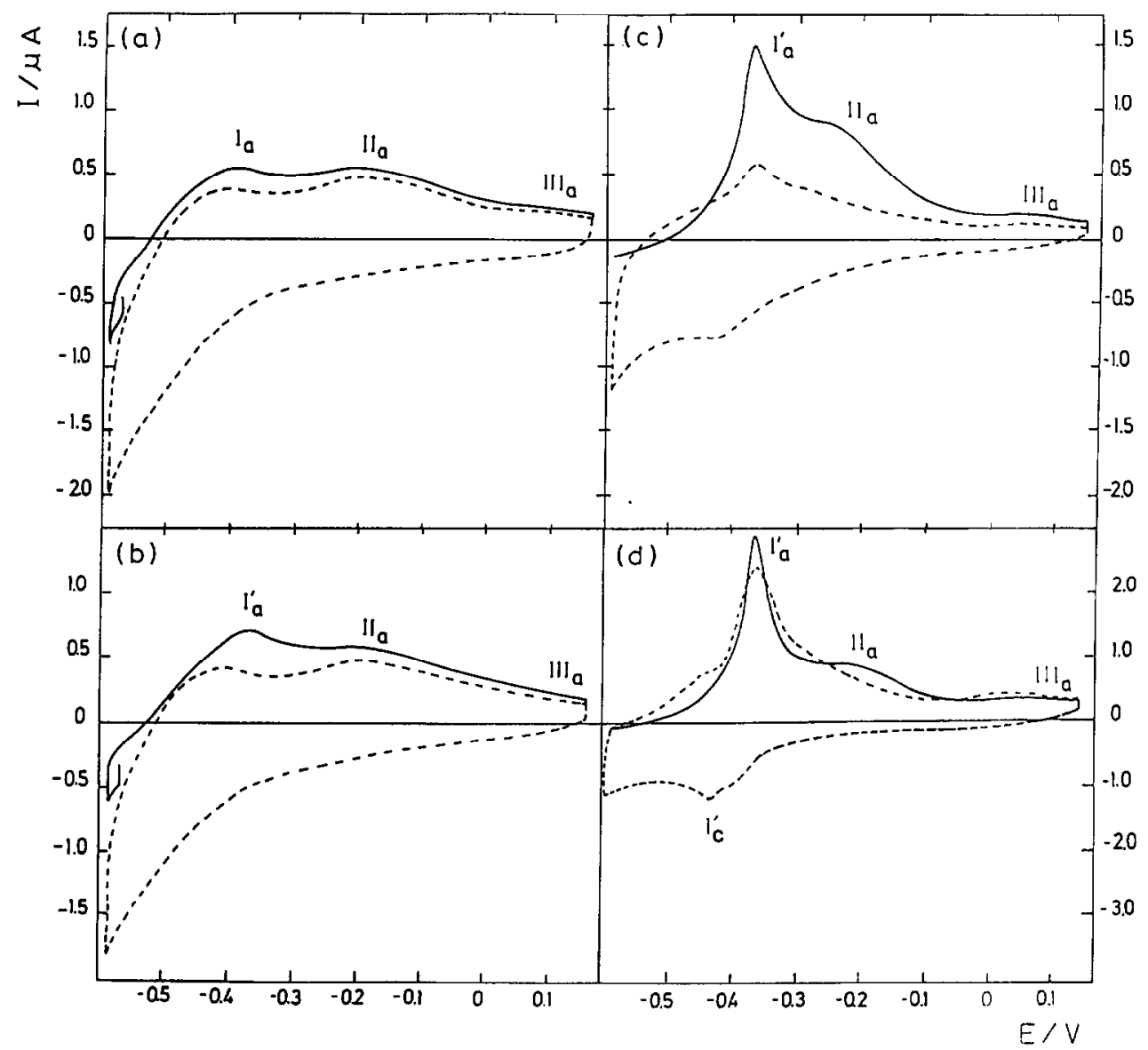

Fig. 8. Cyclic voltammograms of Cd UPD-anodic stripping for columnar Ag WEs at $0.02 \mathrm{~V} \mathrm{~s}^{-1}$ including a potential holding at $E_{\mathrm{h}}=-0.575 \mathrm{~V}$ applied in the negative-going potential scan during different times $t_{\mathrm{h}}$ at $25^{\circ} \mathrm{C}(-\mathrm{CV} 1 ;---\mathrm{CV} 2):(\mathrm{a}) t_{\mathrm{h}}=1 \mathrm{~min}$; (b) $t_{\mathrm{h}}=10 \mathrm{~min} ;$ (c) $t_{\mathrm{h}}=4 \mathrm{~h} ;(\mathrm{d}) t_{\mathrm{h}}=14 \mathrm{~h}$. 
different types of interactions between surface $\mathrm{Ag}$ and $\mathrm{Cd}$ atoms. The surface roughness relaxation probably occurs at a rate close to the Ag electrodeposition rate.

\subsubsection{The influence of $E_{h}$ on the $C d$ underpotential} deposition-anodic stripping voltammetric charge. Charge evaluation from voltammograms (Figs. 13 and 14) was attempted for dendritic $\mathrm{Ag}$ WEs $\left(q_{\mathrm{Ag}}=50 \mathrm{mC}\right.$ $\mathrm{cm}^{-2}$ ) for $t_{\mathrm{h}}=15 \mathrm{~min}$ (Figs. 13(a) and 14(a)) and $t_{\mathrm{h}}=$ $30 \mathrm{~min}$ (Figs. 13(b) and 14(b)) covering the $-0.35 \mathrm{~V}<$ $E_{\mathrm{h}}<-0.588 \mathrm{~V}$ range by setting all variables except $E_{\mathrm{h}}$. From these $\mathrm{Cd}$ anodic stripping voltammograms (Fig. 13), a decrease in charge $Q_{-}$at the negative potential side of peak Ia, which corresponds to a decrease in the amount of weakly bound $\mathrm{Cd}$, and an increase in charge $Q_{+}$at the positive potential side of peak Ia, which represents an increase in the amount of strongly bound $\mathrm{Cd}$, are observed. Evaluation of these charges was attempted by means of the scheme illustrated in the inset to Fig. 14(a). In this case, the $Q_{-}$vs. $E_{\mathrm{h}}$ (Figs. 14(a) and 14(b), open circles) and $Q_{+}$vs. $E_{\mathrm{h}}$
(Figs. 14(a) and 14(b), solid circles) plots show two interesting features irrespective of $t_{\mathrm{h}}$, namely an increase in $Q_{+}$when $E_{\mathrm{h}}>E_{\mathrm{t}}$, where $E_{\mathrm{t}} \approx-0.4 \mathrm{~V}$ is a threshold potential value, and a change in $Q_{\text {- over a }}$ rather small $E_{\mathrm{h}}$ range, which goes through a maximum value at $E_{\mathrm{h}} \approx-0.5 \mathrm{~V}$. Thus $Q_{+}$and $Q_{-}$increase with a common slope from $E_{\mathrm{t}}$ up to $E_{\mathrm{h}} \approx-0.5 \mathrm{~V}$, indicating that the decrease in the weakly bound Cd UPD atoms is accompanied by an increase in the strongly bound Cd UPD atoms. However, the $Q_{+}$increase from $E_{\mathrm{h}}$ to $E_{\mathrm{r}}$ is due not only to the increase in peak Ia but also to the increase in peak $\mathrm{I}_{\mathbf{a}}^{\prime}$, whose contribution arises from the removal of $\mathrm{Cd}$ atoms from the $\mathrm{Cd}+\mathrm{Ag}$ surface.

\subsection{Cd underpotential deposition-anodic stripping on $\mathrm{Cd}+\mathrm{Ag}$ alloy}

Voltammograms of a $\mathrm{Cd}+\mathrm{Ag}$ alloy ( $\alpha$ phase) WE in solution II run at $v=0.02 \mathrm{~V} \mathrm{~s}^{-1}$ covering different $E_{\mathrm{sc}}$ and $E_{\mathrm{sa}}$ values (Fig. 15) show a first region extending from $-0.325 \mathrm{~V}$ to $-0.6 \mathrm{~V}$, which is the main $\mathrm{Cd}$
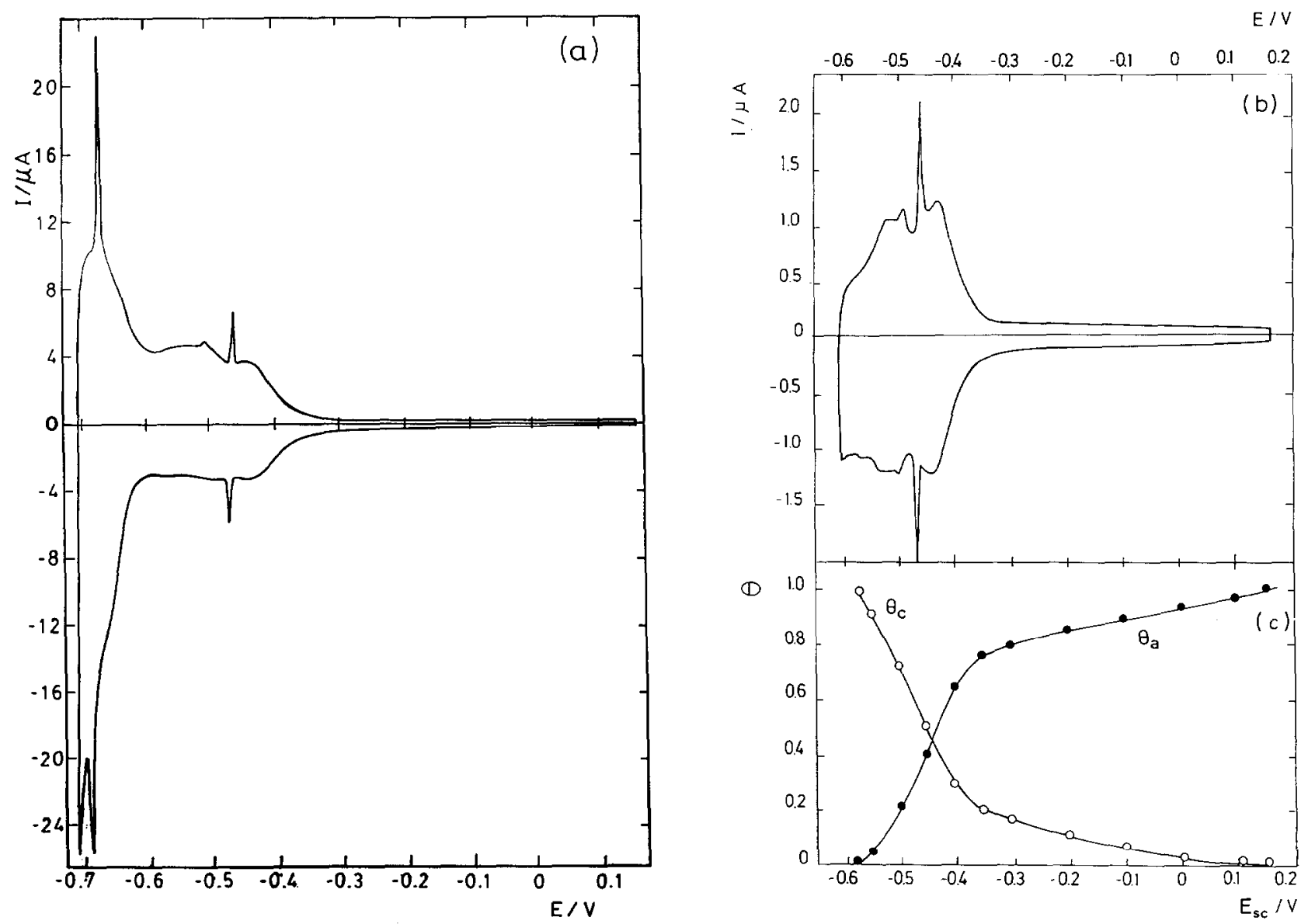

Fig. 9. Cyclic voltammograms of Cd UPD-anodic stripping for dendritic $\mathrm{Ag}$ WEs in solution II at $0.02 \mathrm{~V} \mathrm{~s} \mathrm{~s}^{-1}:$ (a) $E_{\mathrm{sc}}=-0.705 \mathrm{~V}$; (b) $E_{\mathrm{sc}}=-0.585 \mathrm{~V}$. (c) $\theta_{\mathrm{a}}$ vs. $E_{\mathrm{sc}}$ and $\theta_{\mathrm{c}}$ vs. $E_{\mathrm{sc}}$ plots related to (b). Temperature, $25^{\circ} \mathrm{C}$. 


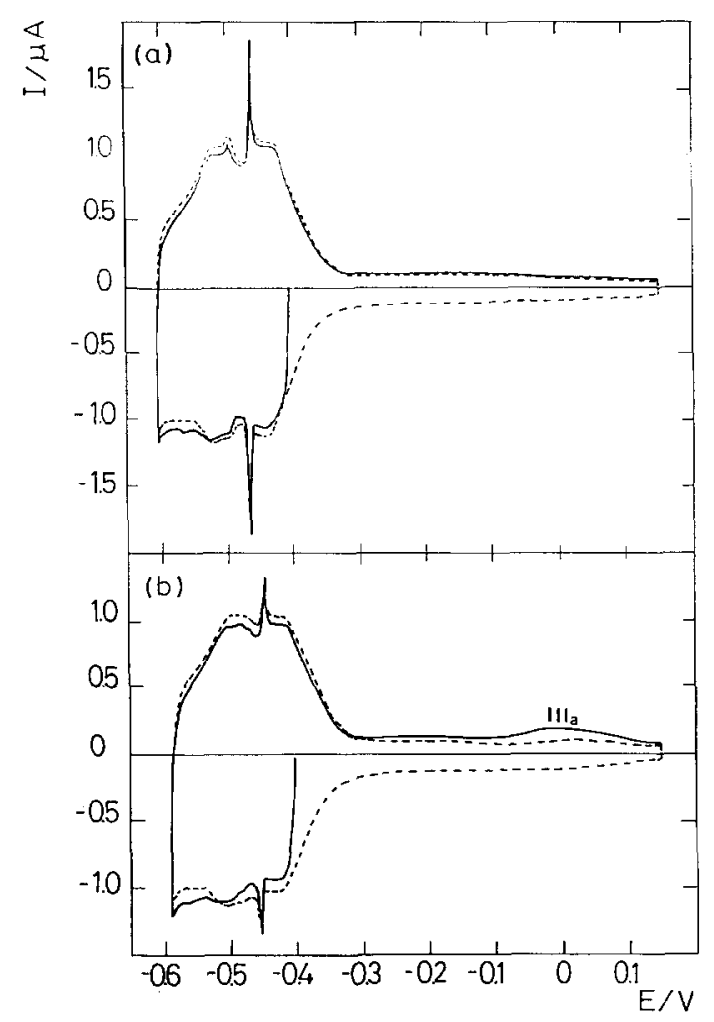

Fig. 10. Cyclic voltammograms of Cd UPD-anodic stripping for dendritic $\mathrm{Ag}$ WEs at $0.02 \mathrm{~V} \mathrm{~s}^{-1}$ including a potential holding at $E_{\mathrm{h}}=-0.40 \mathrm{~V}$ applied in the negative-going potential scan during

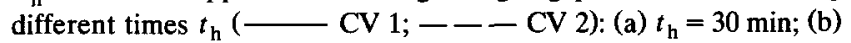
$t_{\mathrm{h}}=3 \mathrm{~h}$. Temperature, $25^{\circ} \mathrm{C}$.

UPD-anodic stripping potential range on $\mathrm{Ag}$, and a second region from $-0.1 \mathrm{~V}$ to $0.2 \mathrm{~V}$, where three broad symmetric peaks related to the anodic stripping

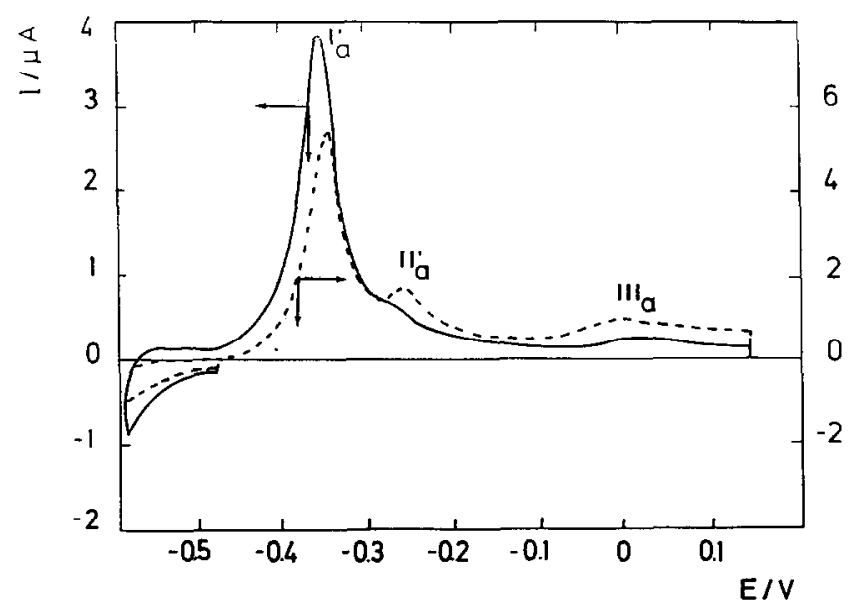

Fig. 11. Cyclic voltammograms of Cd UPD-anodic stripping for a dendritic $\mathrm{Ag}$ WEs at $0.02 \mathrm{~V} \mathrm{~s}^{-1}$ including potential holding at $E_{\mathrm{h}}=-0.47 \mathrm{~V}$ applied in the negative-going potential scan for different times $t_{\mathrm{h}}$ at $25^{\circ} \mathrm{C}$ : (—) $t_{\mathrm{h}}=3 \mathrm{~h} ;(--\longrightarrow) t_{\mathrm{h}}=15 \mathrm{~h}$.
TABLE 1. Voltammetric data obtained with dendritic Ag WEs which were held at $E_{\mathrm{h}}=-0.47 \mathrm{~V}$ for different times $t$

\begin{tabular}{rlll}
\hline \multicolumn{1}{l}{$/ \mathrm{s}$} & $Q_{t} / \mathrm{ML}$ & $Q_{\text {Ia }}^{\prime} / \mathrm{ML}$ & $Q_{t}^{\text {upd }} / Q_{t=0}^{\text {upd }}$ \\
\hline 0 & 1 & 0 & 1 \\
300 & 1.04 & 0.02 & 1 \\
600 & 1.07 & 0.10 & 0.968 \\
900 & 1.07 & 0.15 & 0.915 \\
1800 & 1.12 & 0.30 & 0.820 \\
3600 & 1.24 & 0.64 & 0.592 \\
7200 & 1.78 & 1.29 & 0.485 \\
10920 & 1.58 & 1.21 & 0.367 \\
53985 & 2.04 & 2.02 & 0.020 \\
\hline
\end{tabular}

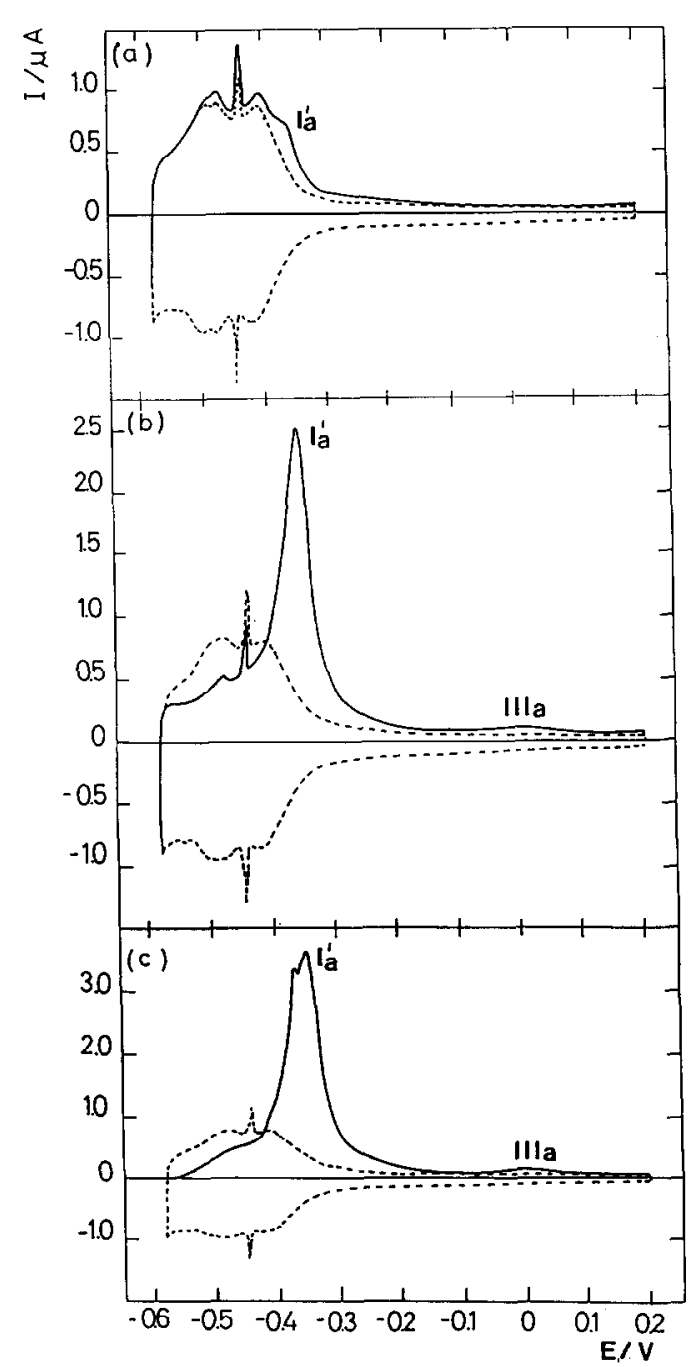

Fig. 12. Cyclic voltammogram of Cd UPD-anodic stripping for a dendritic $\mathrm{Ag}$ WEs at $0.02 \mathrm{~V} \mathrm{~s}^{-1}$ including potential holding at $E_{\mathrm{h}}=-0.575 \mathrm{~V}$ applied in the negative-going potential scan for dif-

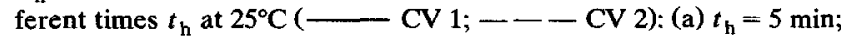
(b) $t_{\mathrm{h}}=30 \mathrm{~min}$; (c) $t_{\mathrm{h}}=76 \mathrm{~min}$. 
TABLE 2. Voltammetric data obtained with dendritic Ag WEs which were held at $E_{\mathrm{h}}=-0.575 \mathrm{~V}$ for different times $t$

\begin{tabular}{rlll}
\hline \multicolumn{1}{l}{ /s } & $Q_{t} / \mathrm{ML}$ & $Q_{\mathrm{ta}}^{\prime} / \mathrm{ML}$ & $Q_{t}^{\mathrm{upd}} / Q_{t=0}^{\mathrm{upd}}$ \\
\hline 0 & 1 & 0 & 1 \\
60 & 1.07 & 0 & 1 \\
180 & 1.11 & 0.12 & 0.997 \\
300 & 1.15 & 0.17 & 0.983 \\
600 & 1.16 & 0.26 & 0.901 \\
900 & 1.29 & 0.42 & 0.874 \\
1800 & 1.50 & 0.85 & 0.684 \\
3720 & 1.48 & 0.93 & 0.549 \\
5400 & 1.81 & 1.32 & 0.488 \\
9000 & 2.0 & 1.67 & 0.333 \\
14400 & 2.18 & 1.88 & 0.297 \\
46200 & 2.55 & 2.38 & 0.157 \\
\hline
\end{tabular}

of $\mathrm{Cd}$ atoms from the $\mathrm{Cd}+\mathrm{Ag}$ bulk alloy are found. Those peaks assigned to electrochemical reactions at $\mathrm{Cd}+\mathrm{Ag}$ bulk alloy are definitely absent at all types of $\mathrm{Ag}$ WE, even when $E_{\mathrm{sc}}$ is set in the Cd overpotential electrodeposition range (Fig. 16).

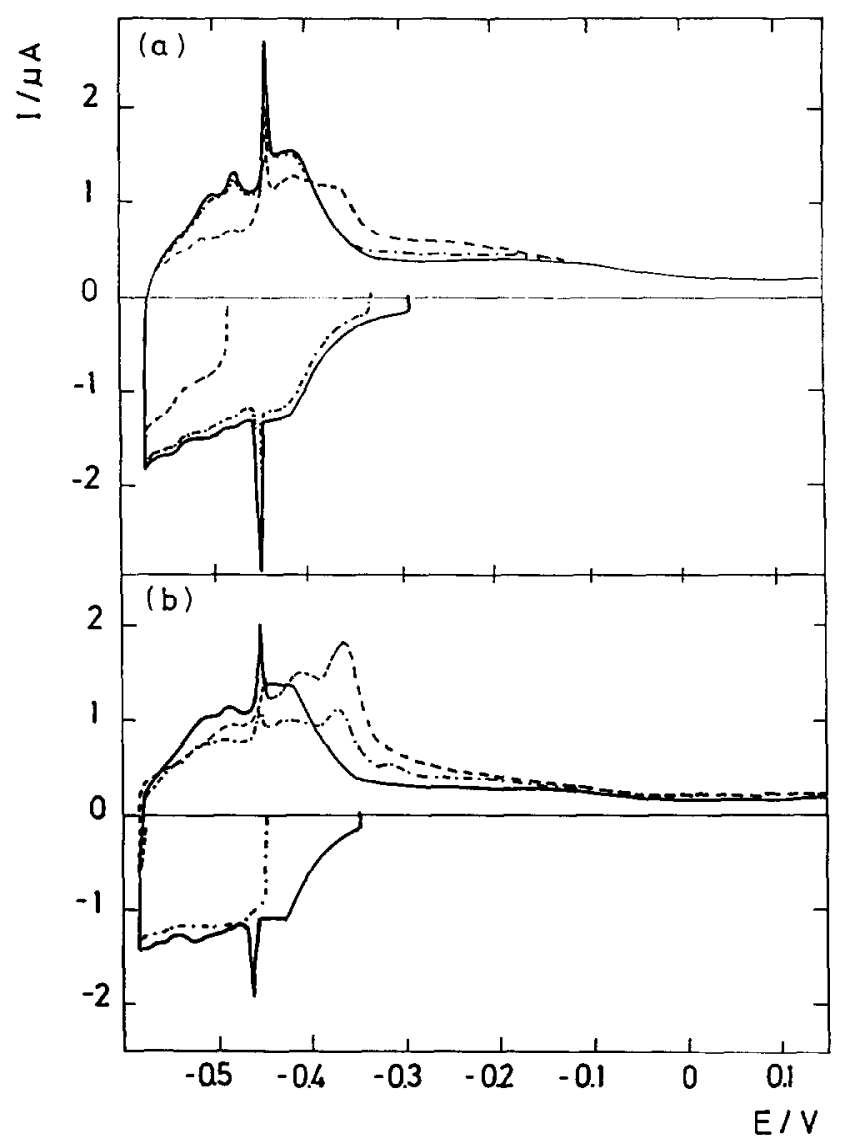

Fig. 13. Cyclic voltammograms of Cd UPD-anodic stripping for dendritic Ag WEs at $0.02 \mathrm{~V} \mathrm{~s}^{-1}$ : (a) $E_{\mathrm{h}}=-0.30 \mathrm{~V}(\longrightarrow), E_{\mathrm{h}}=$ $-0.34 \mathrm{~V}(\cdot-\cdot-\cdot)$ and $E_{\mathrm{h}}=-0.49 \mathrm{~V}(---)$ at $t_{\mathrm{h}}=15 \mathrm{~min}$; (b) $E_{\mathrm{h}}=-0.35 \mathrm{~V}(\longrightarrow), E_{\mathrm{h}}=-0.45 \mathrm{~V}(\cdot-\cdot-\cdot)$ and $E_{\mathrm{h}}=-0.59 \mathrm{~V}$ $(-\ldots-)$ at $t_{\mathrm{h}}=30 \mathrm{~min}$. Temperature, $25^{\circ} \mathrm{C}$.

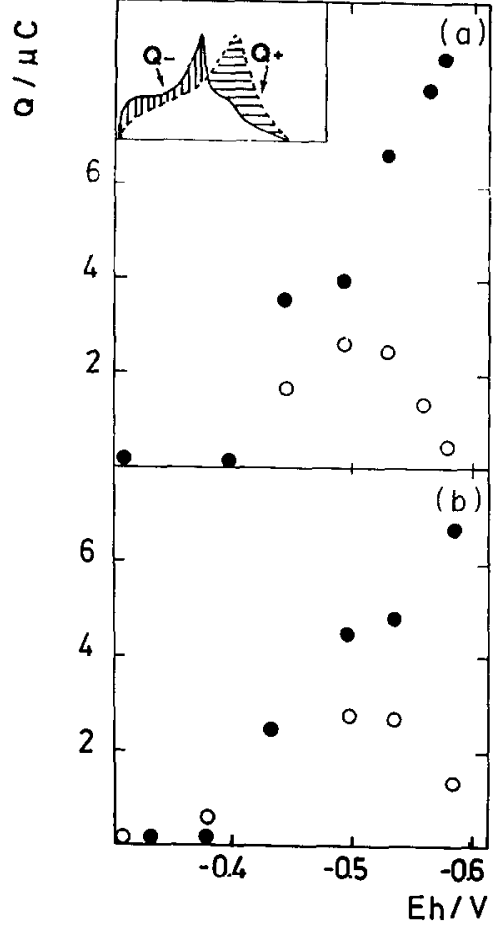

Fig. 14. Charge decrease $Q_{-}(0)$ and charge increase $Q_{+}(\bullet)$ vs. holding potential $E_{\mathrm{h}}$ for (a) $t_{\mathrm{h}}=15 \mathrm{~min}$ and (b) $t_{\mathrm{h}}=30 \mathrm{~min}$. Data correspond to the cyclic voltammograms shown in Fig. 13. A scheme for the calculation of $Q_{-}$and $Q_{+}$is shown in the inset. Apparent electrode area, $0.04 \mathrm{~cm}^{2}$; temperature, $25^{\circ} \mathrm{C}$.

\subsection{X-ray photoelectron spectra}

$\mathrm{X}$-ray photoelectron spectra of columnar-Ag-coated WEs, which were held at $E_{\mathrm{h}}=-0.57 \mathrm{~V}$ for $t_{\mathrm{h}}=10 \mathrm{~h}$ in solution I, show the $367.9 \mathrm{eV}$ signal which corresponds to $\mathrm{Ag}$ and the $404.8 \mathrm{eV}$ signal of $\mathrm{Cd}$ which emerges as a weak signal from the background [29]. According to X-ray photoelectron spectra, the amount of $\mathrm{Cd}$ on this type of $\mathrm{Ag}$ substrate can be estimated as that expected from $\theta_{\mathrm{Cd}} \approx 1 \mathrm{ML}$ although it lies in the detection limit of the technique. Similar results were

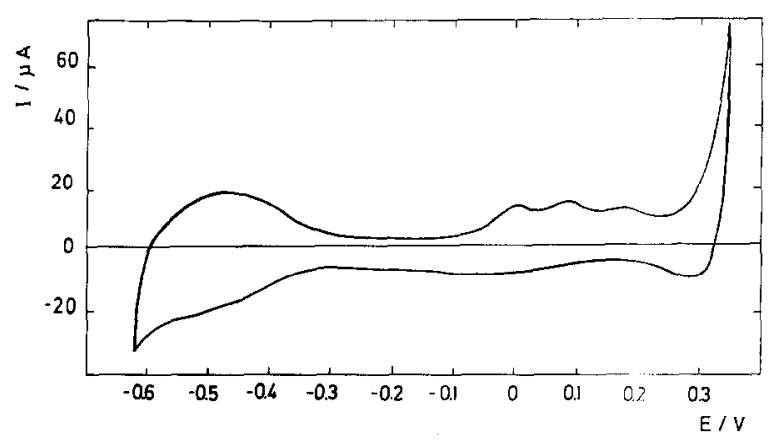

Fig. 15. Cyclic voltammograms of Cd UPD-anodic stripping on a $\mathrm{Cd}+\mathrm{Ag}$ alloy $\mathrm{WE}$ in solution II at $0.02 \mathrm{~V} \mathrm{~s}^{-1}$ : apparent electrode area, $1 \mathrm{~cm}^{2}$; temperature, $25^{\circ} \mathrm{C}$. 


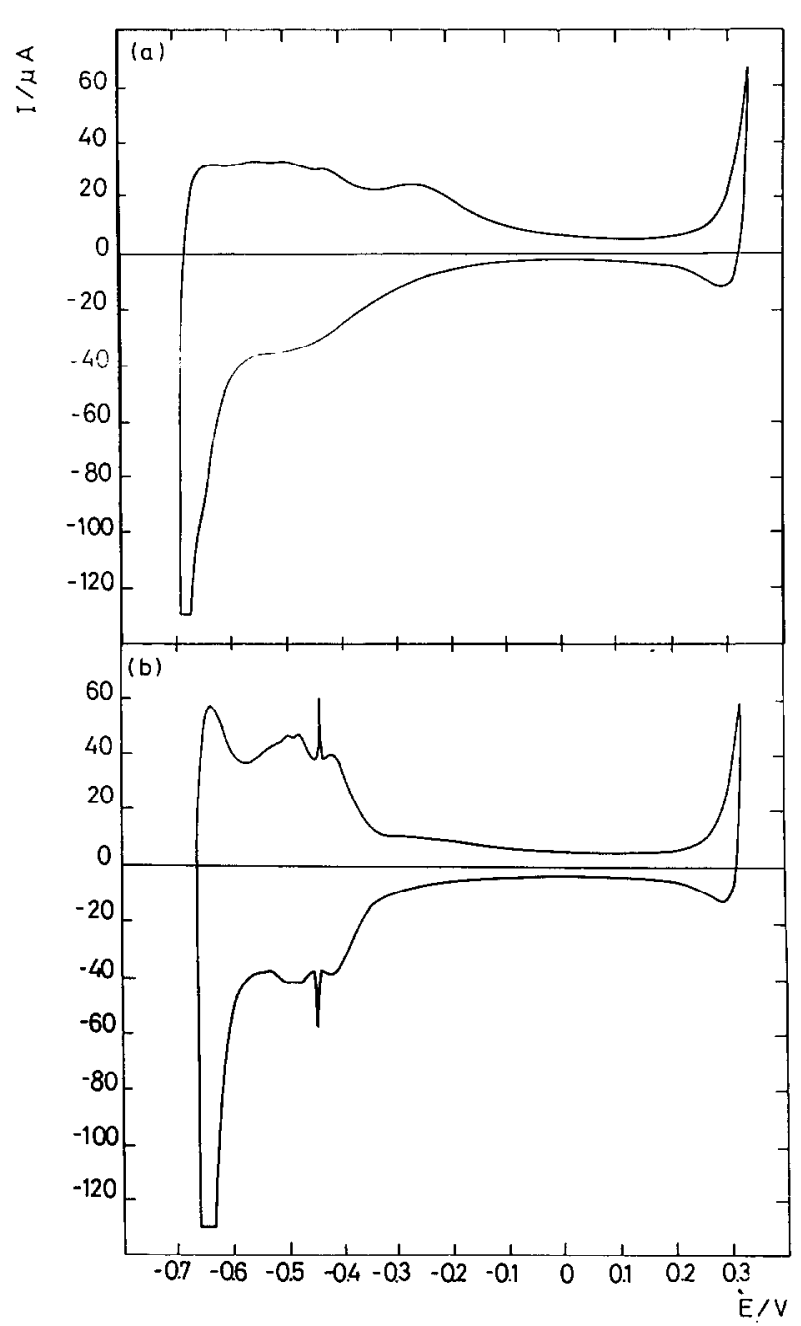

Fig. 16. Cyclic voltammograms of Cd UPD-anodic stripping from $E_{\mathrm{sc}}=-0.65 \mathrm{~V}$ to $E_{\mathrm{sa}}=0.31 \mathrm{~V}$ in solution II at $0.02 \mathrm{~V} \mathrm{~s}^{-1}$ : (a) Columnar Ag WE (apparent electrode area $0.89 \mathrm{~cm}^{2}$ ); (b) dendritic Ag WE (apparent electrode area $1.15 \mathrm{~cm}^{2}$ ). Temperature, $25^{\circ} \mathrm{C}$.

obtained after holding the potential at $E_{\mathrm{h}}$ for $t_{\mathrm{h}}=24 \mathrm{~h}$. After Ar ion bombardment, the Cd signal completcly disappears at ca. $0.5 \mathrm{~nm}$. This result indicates that $\mathrm{Cd}$ penetration depth into the substrate is no greater than $2 \mathrm{ML}$.

\section{Discussion}

\subsection{The probable structures of $\mathrm{Ag}$ electrodeposits}

The structure of columnar metal electrodeposits has been thoroughly discussed in recent papers $[17,19]$. It consists of a collection of nanometer-size columns with smooth tips. The fluctuations in the height of columns lead to a self-affine fractal surface for lengths larger than the average columnar size [19]. However, in this case, as the $\mathrm{Cd}$ and $\mathrm{Pb}$ atom sizes are smaller than the average columnar size, the fractal character of these surfaces is not observed for the electrodeposition of those metal atoms and the Ag substrate behaves as a Euclidean polycrystalline surface.

Furthermore, the structure of dendritic $\mathrm{Ag}$ electrodeposits can be described in terms of self-similar fractals for lengths larger than the size of the smaller branch, which is in the micrometer range [18]. In addition, the individual branches are stepped single crystals with (111) faces as revealed by TED and STM measurements respectively. Thus $\mathrm{Cd}$ and $\mathrm{Pb}$ atom electrodeposition occurs on crystalline surfaces formed by $\mathrm{Ag}(111)$ terraces and steps.

\subsection{The multiplicity of $C d$ underpotential deposition} peaks for $\theta_{c} \leq 1$ and possible surface structures

The structure of $\mathrm{Ag}$ electrodeposits at the nanometer level explains the voltammetric characteristics of $\mathrm{Cd}$ and $\mathrm{Pb}$ electrodeposition-anodic stripping peaks. From the electrochemical standpoint, the main difference between columnar and dendritic $\mathrm{Ag}$ electrodeposits lies in the definition and the reversibility of $\mathrm{Cd}$ UPD-anodic stripping peaks appearing in the $-0.59 \mathrm{~V}$ to $0.15 \mathrm{~V}$ range. For both $\mathrm{Ag}$ substrates the voltammograms show a low Cd UPD range from $-0.59 \mathrm{~V}$ to ca. $-0.4 \mathrm{~V}$ where complementary voltammetric peaks are observed, and a high Cd UPD range from $-0.4 \mathrm{~V}$ to $0.15 \mathrm{~V}$ where the voltammetric peaks are due to alloyed $\mathrm{Cd}$, as confirmed by $\mathrm{CV}$ data on $\mathrm{Cd}+\Lambda \mathrm{g}$ alloys (Fig. 15). For columnar $\mathrm{Ag}$ electrodeposits the broad current peaks recorded for $\mathrm{Cd}$ and $\mathrm{Pb}$ UPD-anodic stripping voltammograms are consistent with a disordered polycrystalline surface. Conversely, voltammograms corresponding to dendritic Ag electrodeposits exhibit sharp and reversible current peaks which closely resemble those obtained on stepped $\mathrm{Ag}(111)$ single crystals $[10,24,25]$, in agreement with STM and TED data.

A model for the exchange between $\mathrm{Cd}$ atoms at the surfacc and $\mathrm{Ag}$ atoms at the first $\mathrm{Ag}$ layer is shown schematically in Fig. 17 (schemes A and B). In this model $1 \mathrm{ML}$ of $\mathrm{Cd}$ can produce two layers of a $1: 1$ $\mathrm{Cd}+\mathrm{Ag}$ alloy. Furthermore, a new UPD Cd ML can be formed on top of the first $\mathrm{Cd}+\mathrm{Ag}$ layer (schemes $\mathrm{C}$ and D). Accordingly, the anodic stripping of $\mathrm{Cd}$ species from the alloy surface should differ from the anodic stripping of a Cd UPD on $\mathrm{Ag}$, as the $\mathrm{Cd}$ atoms are in contact with $\mathrm{Ag}$ and $\mathrm{Cd}$ atoms rather than exclusively with Ag atoms of the substrate. Consequently, a different anodic stripping voltammogram should be observed. The strong distortion of the anodic stripping voltammogram produced by cathodizing supports this assumption. Thus, as the potential is positively shifted from $E_{\mathrm{r}}$ to $0.15 \mathrm{~V}$, the Cd UPD monolayer stripping from $\mathrm{Cd}+\mathrm{Ag}$ alloy should occur first, followed by 
removal of $\mathrm{Cd}$ atoms from the $\mathrm{Ag}+\mathrm{Cd}$ surface. This process is related to peak $I_{a}^{\prime}$, which is located slightly positive with respect to the anodic stripping peak of the strongly bound Cd UPD atoms on Ag. Finally, the $\mathrm{Cd}$ atoms lying in the second $\mathrm{Cd}+\mathrm{Ag}$ layer (schemes $\mathrm{C}$ and $\mathrm{D}$ ) are removed at more positive potentials; this process is assigned to peak III $_{\mathrm{a}}^{\prime}$. This model admits that the overall $\mathrm{Cd}$ stripping charge is equivalent to 2 ML.

\subsection{Kinetics of dermalloy formation}

Let us consider the potentiostatic formation of the $\mathrm{Cd}+\mathrm{Ag}$ dermalloy for $0.6<\theta_{\mathrm{Cd}}<1$. From cxpcrimental results it was concluded that a progressive decrease in the amount of weakly bound Cd UPD atoms is observed irrespective of the $\mathrm{Ag}$ electrode type. This decrease corresponds to increase in alloyed $\mathrm{Cd}$ which is stripped off at potentials even more positive than the anodic stripping of the strongly bound UPD $\mathrm{Cd}$. The rate of penetration of $\mathrm{Cd}$ atoms at the dermalloy level can be obtained by assuming that the process implies $\mathrm{Cd}$ atom "diffusion" through the first $\mathrm{Ag}$ atom layer of a grain-boundary-free surface layer. For such an "unidirectional diffusion" $n(t)$, the number of $\mathrm{Cd}$ atoms on the $\mathrm{Ag}$ surface at time $t$ is related to the number $n(t=0)$ of Cd atoms present on the Ag surface at $t=0$ by $[30]$

$n(t)=n(t=0)$ erf $\left[(a / 4 D t)^{1 / 2}\right]$

where $D$ is the diffusion coefficient of the slowest moving reacting entity and $a$ is the diffusion layer

A

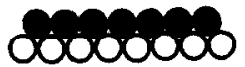

1

B

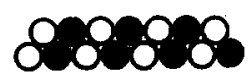

It

C
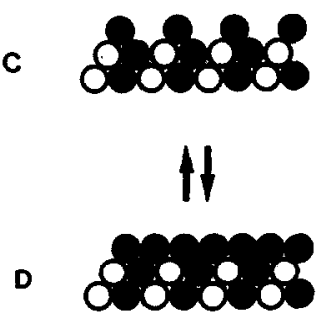

Fig. 17. Simplified scheme of possiblc $\mathrm{Cd}, \mathrm{Cd}+\mathrm{Ag}$ and $\mathrm{Ag}$ overlayer structures on Ag substrates and possible interconversion reactions: $\bullet$ $\mathrm{Cd}$ atoms; $\mathrm{O} \mathrm{Ag}$ atoms.

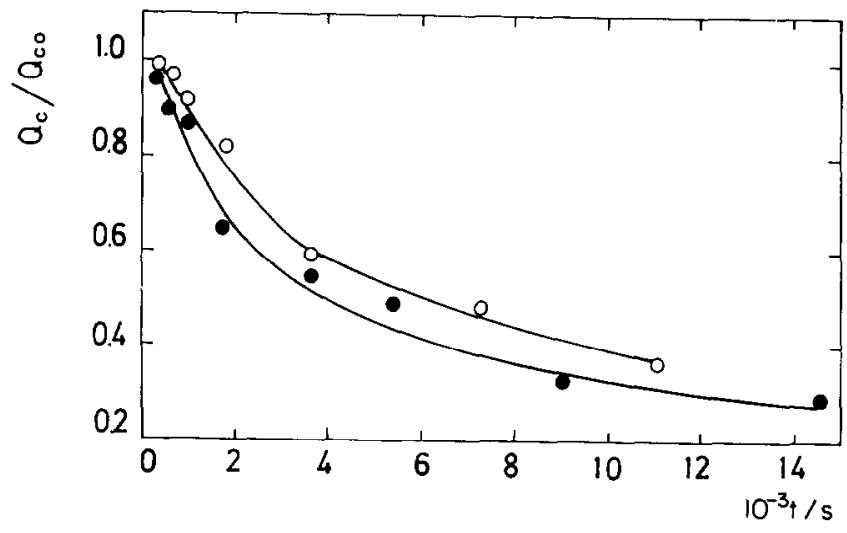

Fig. 18. $Q_{\mathrm{c}} / Q_{\mathrm{c}, 0}$ vs, $t$ plots: $\circ E_{\mathrm{h}}=-0.47 \mathrm{~V} ; \bullet E_{\mathrm{h}}=-0.575 \mathrm{~V}$. Full curves correspond to data calculated using eqn. (2) as described in the text.

thickness. By expressing $n(t)$ in terms of the corresponding voltammetric charge, the following equation is obtained:

$Q_{\mathrm{c}} / Q_{\mathrm{c}, 0}=\operatorname{erf}\left[(a / 4 D t)^{1 / 2}\right]$

where $Q_{\mathrm{c}}$ and $Q_{\mathrm{c}, 0}$ are the Cd UPD charges at $t=t$ and $t=0$ respectively. This equation is plotted as $Q_{\mathrm{c}} / Q_{\mathrm{c}, 0}$ vs. $t$ (Fig. 18) using experimental data obtained at $E_{\mathrm{h}}=-0.47 \mathrm{~V}$ and $E_{\mathrm{h}}=-0.575 \mathrm{~V}$ for a dendritic Ag WE. Experimental plots are compared with those resulting from eqn. (2) using $a=0.29 \mathrm{~nm}$, $D=5.0 \times 10^{-12} \mathrm{~cm}^{2} \mathrm{~s}^{-1}$ for $E_{\mathrm{h}}=-0.47 \mathrm{~V}$ and $D=$ $7.7 \times 10^{-12} \mathrm{~cm}^{2} \mathrm{~s}^{-1}$ for $E_{\mathrm{h}}=-0.575 \mathrm{~V}$. In principle, the agreement between all the experimental data and the curve obtained using eqn. (2) with the parameters given above is reasonably good. The value $a=0.29 \mathrm{~nm}$ used in the calculation is equal to the lattice constant $d_{\mathrm{Cd}}$ of $\mathrm{Cd}$, and it can be justified because in this case the diffusion of $\mathrm{Cd}$ atoms is limited to the first $\mathrm{Ag}$ atom layer, as has been proved by both electrochemical and XPS results. Otherwise, the value of $D$ is in the order of magnitude of those reported for $\mathrm{Cd}$ atom diffusion on a $\mathrm{Cd}+\mathrm{Ag}$ polycrystalline surface [9], but it is about $10^{3}$ times larger than that reported for $\mathrm{Cd}+\mathrm{Ag}$ alloying on single-crystal surfaces [10].

To understand the processes involved in the $\mathrm{Cd}+\mathrm{Ag}$ dermalloy formation, values of the surface diffusion coefficients $D_{\mathrm{sAg}}$ and $D_{\mathrm{sCd}}$ of $\mathrm{Ag}$ and Cd respectively, found in the literature, can be discussed. $D_{\mathrm{sAg}}$ values between $10^{-12}$ and $10^{-9} \mathrm{~cm}^{2} \mathrm{~s}^{-1}$ have been obtained by different experimental methods [31-33]. For $D_{\mathrm{sAg}}$ the smallest value is in accordance with the value resulting from eqn. (2); however, to the best of our knowledge, there are no available data for $D_{\mathrm{sCd}}$ in the literature to be compared with that found from eqn. 
(2). Values of $D_{\mathrm{sAg}}$ and $D_{\mathrm{sCd}}$ can be estimated independently using the equation $[34,35]$

$$
\begin{aligned}
D_{\mathrm{sM}}= & 7.4 \times 10^{2} \exp \left(-15 T_{m} / T\right) \\
& +1.4 \times 10^{-2} \exp \left(-6.5 T_{\mathrm{m}} / T\right)
\end{aligned}
$$

where $D_{\mathrm{sM}} \mathrm{cm}^{2} \mathrm{~s}^{-1}$ is the surface diffusion coefficient of the metal $\mathrm{M}, T_{\mathrm{m}} / \mathrm{K}$ is the melting temperature of $\mathrm{M}$ and $T / \mathrm{K}$ is the working temperature. The validity of eqn. (3) has been proved through the evaluation of $D_{\text {sAu }}$ for $\mathrm{Au}$ in electrolyte solutions using different experimental methods [36-38]. For $T=298 \mathrm{~K}$, eqn. (3) gives $D_{\mathrm{sAg}}=2.13 \times 10^{-14} \mathrm{~cm}^{2} \mathrm{~s}^{-1}$ and $D_{\mathrm{sCd}}=2.9 \times$ $10^{-8} \mathrm{~cm}^{2} \mathrm{~s}^{-1}$. The value of $D_{\mathrm{sAg}}$ resulting from eqn. (3) approaches the smallest $D_{\mathrm{sAg}}$ value determined in this work, i.e. $D_{\mathrm{sCd}} \gg D_{\mathrm{sAg}}$. Therefore the formation of the $\mathrm{Cd}+\mathrm{Ag}$ surface alloy can be explained by an atom exchange mechanism and step growth $[39,40]$ controlled by the surface mobility of $\mathrm{Ag}$ atoms at the surface $\mathrm{Ag}+\mathrm{Cd}$ layer. Hence the kinetics of $\mathrm{Cd}+\mathrm{Ag}$ dermalloy formation, particularly for $\theta_{\mathrm{Cd}} \rightarrow 0$, would be determined by the $\mathrm{Ag}$ surface atom diffusion as the rate-controlling step. However, for $\theta_{\mathrm{Cd}}>0.6$, step motion at the substrate may contribute substantially to dermalloy formation as the $\mathrm{Ag}(111)$ dendritic surface provides a large number of steps. This explanation, which has been proposed for $\mathrm{Pb}+\mathrm{Ag}$ alloying [12-14], is consistent with $\theta_{\mathrm{Cd}} \approx 2 \mathrm{ML}$.

Cd UPD at potentials close to $E_{\mathrm{r}}$ might also involve both two-dimensional (2D) and three-dimensional (3D) island formation, as the $2 \mathrm{D} \leftrightarrow 3 \mathrm{D} \mathrm{Cd}$ adatom equilibrium at the monolayer level which has been found for different systems [41-43] probably occurs for $\mathrm{Cd}$ on $\mathrm{Ag}$. For $\mathrm{Pb}$ UPD on $\mathrm{Ag}$ at potentials close to $E_{\mathrm{r}}$ the $2 \mathrm{D} \rightarrow 3 \mathrm{D}$ surface atom rearrangement can be caused by strains generated by the different adsorbate and substrate atomic sizes [44-46]. In principle, this situation can be applied to the $\mathrm{Cd}+\mathrm{Ag}$ system because of the different size of atoms, i.e. $d_{\mathrm{Cd}}=0.299 \mathrm{~nm}$ and $d_{\mathrm{Ag}}=0.289 \mathrm{~nm}$. This type of process leading to uncovered $\mathrm{Ag}$ domains could favour dermalloy formation through a place-exchange mechanism with the predominant participation of weakly bound $\mathrm{Cd}$ and substrate atoms.

\subsection{Possible bulk alloy formation}

Under the experimental conditions of this work the contribution of $\mathrm{Cd}+\mathrm{Ag}$ bulk alloying becomes negligible. However, as observed for $\theta_{c}>1$, bulk $\mathrm{Cd}+\mathrm{Ag}$ alloying would imply the penetration of $\mathrm{Cd}$ atoms into bulk Ag, a process which may either follow or accompany $\mathrm{Cd}+\mathrm{Ag}$ dermalloy formation. Usually, bulk alloying occurs much more slowly than dermalloying. Bulk alloying kinetics can frequently be described through the formation of vacancies followed by atomic vacancy interdiffusion [47], as has recently been discussed for the penetration of $\mathrm{Ag}$ into bulk $\mathrm{Pt}$ [16]. Previously reported data about $\mathrm{Cd}+\mathrm{Ag}$ alloy formation at different $\mathrm{Ag}$ single-crystal surfaces, as well as polycrystalline $\mathrm{Ag}[9,10]$ mostly based on the condition that $\theta>1$, involved a penetration of $\mathrm{Cd}$ into bulk $\mathrm{Ag}$ which was equivalent to a $\mathrm{Cd}$ layer of thickness about $10 \mathrm{ML}$. Provided that grain-boundary-free Ag substrates were employed, these results are likely to be related to $\mathrm{Cd}+\mathrm{Ag}$ bulk formation following a type of complex kinetics similar to that described previously.

\section{Acknowledgments}

Authors thank the Consejo Nacional de Investigaciones Científicas y Técnicas (CONICET, Argentina) for financial support of this work. AHC thanks CONICET, Argentina, and Universidad de La Laguna, Spain, for travelling grants to participate in this research work.

\section{References}

$1 \mathrm{~J}$. Bénard, Adsorption on Metal Surfaces. Studies in Surface Science and Catalysis, Vol. 13, Elsevier, Amsterdam, 1983.

2 E.B. Budevski in B.E. Conway, J.O'M. Bockris, E. Yeager, S.U.M. Khan and R.E. White (Eds.), Comprehensive Treatise of Electrochemistry, Vol. 7, Plenum, New York, 1983.

3 D.M. Kolb in H. Gerischer and C. Tobias (Eds.), Advances in Electrochemistry and Electrochemical Engineering, Vol. 11, Wiley, New York, 1978.

4 R. Adzic in H. Gerischer and C. Tobias (Eds.), Advances in Electrochemistry and Electrochemical Engineering, Vol. 13, Wiley, New York, 1984.

5 S. Szabó, Int. Rev. Phys. Chem., 10 (1991) 207.

6 R.C. Salvarezza and A.J. Arvia, Electrochim. Acta, 33 (1988) 1031.

7 R.C. Salvarezza, D.V. Vásquez Moll, M.C. Giordano and A.J Arvia, J. Electroanal. Chem., 213 (1986) 301.

8 D.C. Alonzo and B.R. Scharifker, J. Electroanal. Chem., 274 (1989) 167.

9 E. Schmidt, M. Christen and P. Beyeler, J. Electroanal. Chem., 42 (1973) 275.

$10 \mathrm{H}$. Bort, K. Jüttner, W.J. Lorenz and G. Staikov, Electrochim. Acta, 28 (1983) 993.

11 D. Aberdam, C. Salem, R. Durand and R. Faure, Surf. Sci., 239 (1990) 71.

12 B. Parajón Costa, J.C. Canullo, R.C. Salvarezza, D.V. Vásquez Moll, M.C. Giordano and A.J. Arvia, J. Electroanal. Chem., 244 (1988) 261.

13 N. Dimitrov, A. Popov, T. Vitanov and E. Budevski, Electrochim. Acta, 36 (1991) 2077.

14 A. Popov, N. Dimitrov, O. Velev, T. Vitanov and E. Budevski, Electrochim. Acta, 34 (1989) 265.

15 W. Obretenov, U. Schmidt, W.J. Lorenz, G. Staikov, E. Budevski, D. Carnal, U. Müller, H. Siegenthaler and E. Schmidt, J. Electrochem. Soc., 140 (1993) 692.

16 P. Ocón, P. Herrasti, C. Palacio, M.E. Vela, R.C. Salvarezza, L. Vázquez and A.J. Arvia, Electrochim. Acta, in press. 
17 P. Carro, A. Hernández Creus, S. González, R.C. Salvarezza and A.J. Arvia, J. Electroanal. Chem., 310 (1991) 361.

18 A. Hernández Creus, P. Carro, S. González, R.C. Salvarezza and A.J. Arvia, J. Electrochem. Soc., 139 (1992) 1064.

19 R.C. Salvarezza and $\Lambda . J$. Arvia, J. Phys. Paris, in press.

20 M. Hansen and K. Anderco, Constitution of Binary Alloys, McGraw-Hill, New York, 1958.

21 A.J. Bard, R. Parsons and J. Jordan (Eds.), Standard Potentials in Aqueous Solution, International Union of Pure and Applied Chemistry, Dekker, New York, 1985.

22 International Critical Tables, Vol II, McGraw-Hill, New York, 1927, p. 421.

23 E. Macchi, Makromol. Chem., 191 (1990) 2217.

24 K. Takayanagi, D.M. Kolb, K. Kambe and G. Lehmpfuhl, Surf. Sci., 100 (1980) 407.

25 T. Vitanov, A. Popov, G. Staikov, E. Budevski, W.J. Lorenz and E. Schmidt, Electrochim. Acta, 31 (1986) 981.

26 P. Herrasti, P. Ocón, L. Vázquez, R.C. Salvarezza, J.M. Vara and A.J. Arvia, Phys. Rev. A, 45 (1992) 7440.

27 J. Gómez, L. Vázquez, A.M. Baró, C. Alonzo, E. González, J. González Velasco and A.J. Arvia, J. Electroanal. Chem., 240 (1988) 77.

28 L. Vázquez, J. Gómez, A.M. Baró, N. García, M.L. Marcos, J. González Velasco, J.M. Vara, A.J. Arvia, J. Presa, A. García and M. Aguilar, J. Am. Chem. Soc., 109 (1987) 1730.

29 W.M. Riggs, L.E. Davis, J.F. Moulder and G.E. Muilenberg in C.D. Wagner (Ed.), Handbook of X-ray Photoelectron Spectroscopy, Perkin-Elmer Corporation, 1978.

$30 \mathrm{~J}$. Crank, The Mathematics of Diffusion, Clarendon Press, Oxford, 1975, p. 13.

31 A. Kapnor, R.T. Yang and C. Wong, Catal. Rev. Sci. Eng., 31 (1989) 129.
32 J.M. Blakely, Prog. Mater. Sci., 10 (1963) 395.

33 H.P. Bonzel, in J.M. Blakely (Ed.), Surface Physics of Materials, Academic Press, New York, 1975.

34 N.A. Gojstein, J.J. Burke, N.L. Reed and V. Weiss (Eds.), Surface and Interfaces I, Syracuse University Press, Syracuse, NY, 1967, p. 271.

35 G.E. Rhead, Surf. Sci., 47 (1975) 207.

36 C. Alonso, R.C. Salvarezza, J.M. Vara, A.J. Arvia, L. Vázquez, A. Bartolomé and A.M. Baró, J. Electrochem. Soc., 137 (1990) 261.

37 D. Trevor and C.E.D. Chidsey, J. Vac. Sci. Technol., 9 (1991) 964.

38 C. Alonso, R.C. Salvarezza, J.M. Vara and A.J. Arvia, Electrochim. Acta, 35 (1990) 1331

39 N. Dimitrov, A. Popov, D. Kashchiev, T. Vitanov and E. Budevski, Electrochim. Acta, 36 (1991) 1259.

40 N. Dimitrov, A. Popov, D. Kashchiev, T. Vitanov and E. Budevski, Flectrochim. Acta, 36 (1991) 2077.

41 D. Margheritis, R.C. Salvarezza, M.C. Giordano and A.J. Arvia, J. Electroanal. Chem., 229 (1987) 327.

42 M.W. Breiter, Electrochim. Acta, 34 (1989) 1119.

43 W. Visscher and A.P. Cox, Electrochim. Acta, 37 (1992) 2245.

44 H. Bort, K. Jüttner, W.J. Lorenz, G. Staikov and E. Budevski, Electrochim. Acta, 28 (1983) 985.

45 W.J. Lorenz, L.M. Gassa, V. Schmidt, W. Obretenov, G. Staikov, V. Bostanov and E. Budevski, Electrochim. Acta, 37 (1992) 2173.

46 G. Staikov, E. Budevski, W. Obretenov and W.J. Lorenz, J. Electroanal. Chem., 349 (1993) 355.

47 A.J.E. Welch in W.E. Garner (Ed.), Chemistry of the Solid State, Butterworths, London, 1955, Ch. 12, p. 307. 